\title{
Análisis integrado de construcciones históricas: secuencia estratigráfica y diagnóstico patológico. Aplicación en la iglesia de Santa Clara (Córdoba)*
}

\section{Integrated analysis of historical constructions: stratigraphic sequence and pathological diagnosis. Application to the church of Santa Clara (Cordoba)}

\author{
Rafael Martín Talaverano ${ }^{1}$ \\ Urbe pro Orbe \\ Leandro Cámara Muñoz \\ Fundación Catedral Santa María \\ José Ignacio Murillo Fragero 3 \\ Urbe pro Orbe
}

\begin{abstract}
RESUMEN
El acercamiento al edificio histórico como el conjunto de construcciones y transformaciones que se han ido produciendo a lo largo de su historia permite entender con rigor la naturaleza evolutiva del mismo. En este sentido, la metodología de la Arqueología de la Arquitectura, basada en el análisis estratigráfico, aporta el marco teórico adecuado para el análisis de la secuencia evolutiva de los edificios existentes. El presente artículo ofrece una metodología novedosa para el estudio de las construcciones históricas que integra el análisis patológico en la secuencia estratigráfica. Gracias a ella, se obtiene una visión evolutiva de la estructura y de sus problemas patológicos, alcanzándose una mejor comprensión de los mismos. Además, permite obtener unos resultados más rigurosos, eficaces y respetuosos con los valores patrimoniales, potenciándose la optimización de los recursos para la conservación del patrimonio cultural. Esta propuesta se centra en el caso de estudio llevado a cabo en la antigua mezquita y ahora iglesia del convento de Santa Clara (Córdoba), donde la integración interdisciplinar ha proporcionado las bases para el desarrollo de este trabajo.
\end{abstract}

Palabras clave: patrimonio cultural; secuencia evolutiva; Arqueología de la Arquitectura; análisis patológico; análisis estructural; restauración arquitectónica.

\begin{abstract}
The approach to the historical building by means of the sequence of constructions and transformations which take place throughout its whole life allows to understand rigorously its evolutionary nature. In this way, the methodology of the archaeology of architecture, based on the stratigraphical analysis, provides the adequate theoretical frame to study the evolutionary sequence of existing buildings. The present paper
\end{abstract}

\footnotetext{
* Los trabajos y los materiales presentados en el presente artículo en torno a la iglesia del convento de Santa Clara se han desarrollado según se muestra en la siguiente ficha técnica:

- Promotor de los trabajos: Ayuntamiento de Córdoba.

- Levantamiento fotogramétrico: Latorre y Cámara, SL, financiado por la Fundación Caja Madrid (2004): http://multimedia.fundacionmontemadrid.es/patrimonio/santaclara/

- Análisis de Arqueología de la Arquitectura: Consejo Superior de Investigaciones Científicas, equipo dirigido por Luis Caballero Zoreda, financiado por la Fundación Caja Madrid (2006-2007): http://multimedia.fundacionmontemadrid.es/patrimonio/santaclara/

- Análisis patológico estructural: Urbe pro Orbe Patrimonio Cultural, S.L. y Leandro Cámara (2016). Encargado por la Gerencia Municipal de Urbanismo del Ayuntamiento de Córdoba.

rmartin@urbeproorbe.com / ORCID iD: http://orcid.org/0000-0002-3811-3954

7900camara@coam.es / ORCID iD: http://orcid.org/0000-0003-4526-2488

jimurillo@urbeproorbe.com / ORCID iD: http://orcid.org/0000-0003-2249-3224
} 
offers an innovative methodology for the study of historical constructions aimed at the integration of the pathological analysis within the stratigraphic sequence. It thus allows to obtain an evolutionary perspective of the structure and their pathological problems, reaching a better comprehension. Besides this, thanks to the proposed methodological approach, more rigorous, efficient and respectful results can be achieved, boosting the optimization of the existing resources for the conservation of cultural heritage. This proposal is focused on a specific case study concerning the old mosque and current church of the convent of Santa Clara (Córdoba), in which the interdisciplinar integration of several profesional profiles allowed us to develop this work.

Keywords: Cultural heritage; evolutionary sequence; Archaeology of Architecture; pathological analysis; architectural restoration.

Recibido: 27-06-2017. Aceptado: 10-07-2017; Publicado online: 03/07/2018.

Cómo citar este artículo / Citation

Martín Talaverano, R., Cámara Muñoz, L. y Murillo Fragero, J. I. 2018: "Análisis integrado de construcciones históricas: secuencia estratigráfica y diagnóstico patológico. Aplicación en la iglesia de Santa Clara (Córdoba)", Arqueología de la Arquitectura, 15: e067. https://doi.org/10.3989/arq. arqt. 2018.001

Copyright: (c) 2018 CSIC. Este es un artículo de acceso abierto distribuido bajo los términos de la licencia de uso y distribución Creative Commons Reconocimiento 4.0 Internacional (CC BY 4.0).

\section{INTRODUCCIÓN}

\section{La esencia compleja de la arquitectura histórica}

La arquitectura histórica tiene unas características singulares que la diferencian de la arquitectura contemporánea de nueva planta. Los edificios construidos en la actualidad responden generalmente a un proyecto concebido de modo unitario, empleando frecuentemente elementos constructivos prefabricados. Por el contrario, el conjunto de construcciones que entendemos como arquitectura histórica (o arquitectura existente en términos más generales) se caracteriza habitualmente por responder a una concepción radicalmente distinta. De hecho, no debemos hablar de un edificio histórico como elemento único, puesto que el objeto que hoy en día existe no es sino el resultado de una serie de construcciones, destrucciones y transformaciones a lo largo de su historia (Fig. 1).

Por ello, no se trata de un edificio, sino de los sucesivos edificios, espacios y usos que han existido durante el tiempo de vida de estas construcciones, de tal modo que lo que observamos en la actualidad no es ni más ni menos que el estado en un momento preciso de este ente evolutivo que han sido y serán varios edificios. De hecho, un edificio construido hoy en día probablemente sufrirá transformaciones en el futuro, por lo que, siendo rigurosos, toda arquitectura es o será arquitectura histórica.

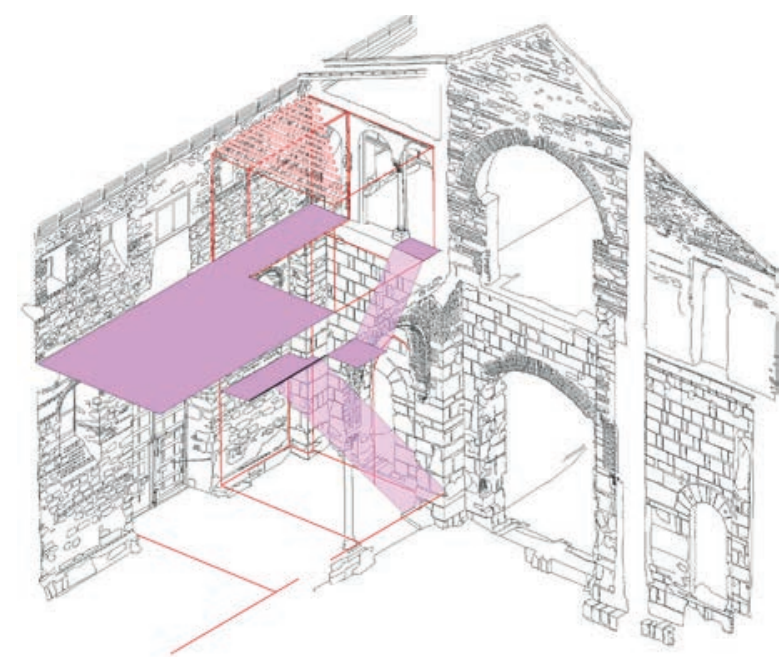

Figura 1. Modelo tridimensional de la iglesia de Santa Clara con hipótesis de propuesta de uso y circulación distintos de los iniciales.

Todo ello obliga a abordar tanto el análisis como la intervención en el patrimonio construido con una base metodológica diferente y especializada. En concreto, se hace necesario entender el edificio histórico desde su naturaleza evolutiva, es decir, como un producto manufacturado realizado en determinados contextos con los que se relaciona, influyendo sustancialmente en la comprensión global del edificio.

En definitiva, podemos concluir que el adecuado análisis del edificio histórico, ya sea para avanzar en su conocimiento o para realizar cualquier intervención, demanda una 
visión evolutiva del mismo considerando su secuencia de transformaciones, así como un trabajo integrado entre distintos especialistas de los distintos ámbitos de conocimiento que confluyen en un único objeto complejo en sí mismo.

\section{Problemática actual}

Sin embargo, no existe una implantación generalizada de este método de análisis en el ámbito de la intervención del patrimonio construido. Si bien desde hace unos años se ha generalizado la realización de lo que ha sido denominado como "estudios previos", estos trabajos no acaban de interrelacionarse de un modo adecuado. Cada especialista responde a sus propias preguntas e intereses de un modo generalmente aislado, de tal modo que el resultado es una suma de documentos yuxtapuestos que ofrecen respuestas poco eficientes a las necesidades reales del conocimiento o la intervención. Puesto que el edificio histórico es el resultado de una serie de relaciones contextuales, los trabajos deben estar bien interrelacionados, de modo que compartan una serie de preguntas comunes que se traten desde distintas ópticas de especialización.

Además, usualmente dichos trabajos se han desarrollado sin considerar la naturaleza evolutiva de los edificios, lo cual puede haber distorsionado los resultados. En el caso concreto de los estudios patológicos de las construcciones históricas, esta situación ha sido bastante habitual, con una absoluta desconexión entre el trabajo desarrollado para determinar las causas de las lesiones existentes y los estudios histórico-arqueológicos. Tradicionalmente han sido campos ajenos entre sí, aunque existe un estrecho vínculo basado en la naturaleza evolutiva y compleja del edificio histórico, puesto que la consideración de su secuencia de transformaciones es esencial para alcanzar una correcta comprensión de los procesos patológicos y de sus causas.

Esta estrecha relación demanda una vez más una metodología de análisis que integre la investigación patológica en la secuencia histórico-constructiva mediante un trabajo coordinado e interdisciplinar de los especialistas que intervienen en dichas áreas de estudio.

\section{Hacia una metodología integrada}

El objetivo fundamental de este artículo recoge por lo tanto las carencias y necesidades anteriormente mencionadas para proponer y describir una metodología innovadora de análisis que integra el diagnóstico patológico en la secuencia evolutiva del edificio histórico. Esta metodología se basa necesariamente en la colaboración interdisciplinar entre profesionales especializados en el análisis de la secuencia histórico-constructiva por un lado y en el estudio patológico de las construcciones históricas por otro (Fig. 2).
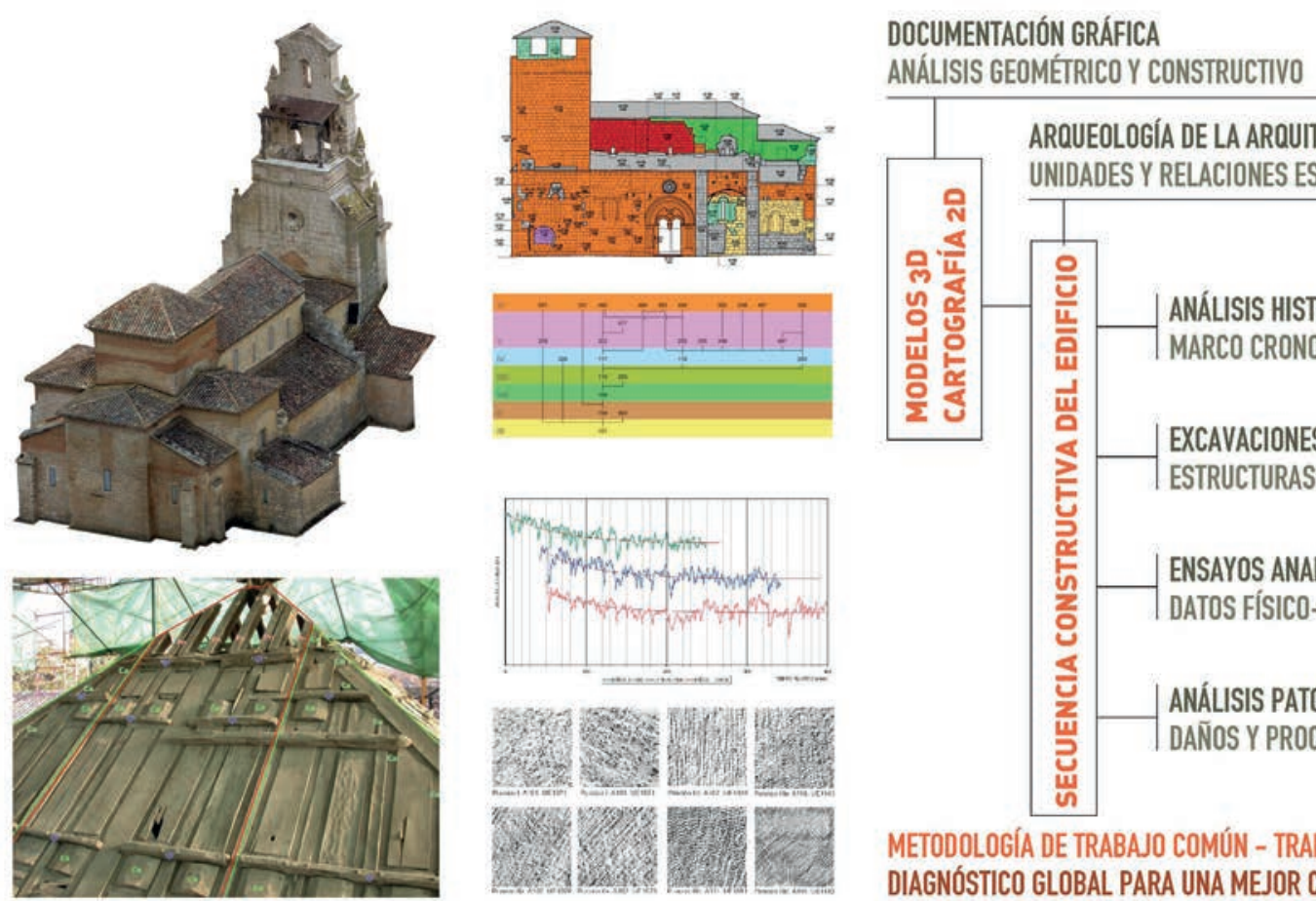

ANÁLISIS GEOMÉTRICO Y CONSTRUCTIVO

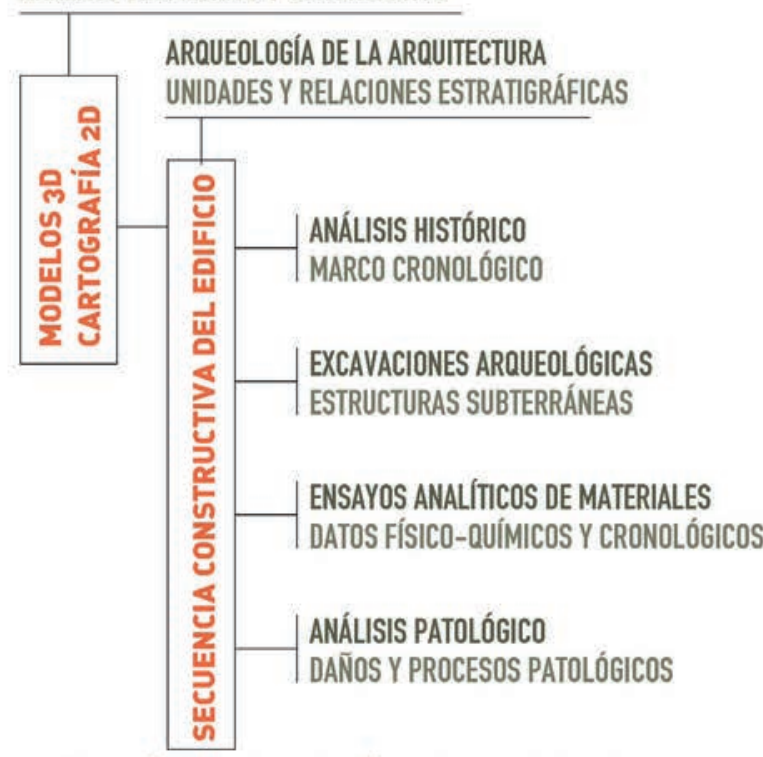

METODOLOGÍA DE TRABAJO COMÚN - TRABAJO DE EQUIPO DIAGNÓSTICO GLOBAL PARA UNA MEJOR CONSERVACIÓN Y DIFUSIÓN

Figura 2. Esquema metodológico de análisis integrado. 
De este modo, se pretende ayudar a lograr resultados más rigurosos, que respeten los valores culturales del edificio y que conduzcan a intervenciones más eficientes, así como a potenciar la optimización de los recursos para la conservación del patrimonio cultural.

Para ilustrar nuestra propuesta, se expondrá el caso de estudio correspondiente a la iglesia del antiguo convento de Santa Clara, en Córdoba, donde gracias a diversas iniciativas promovidas por la Fundación Caja Madrid y el Ayuntamiento de Córdoba, entre los años 2007 y 2016 ha sido posible ensayar este enfoque de análisis y sistematizar la propuesta que a continuación presentamos (Fig. 3).

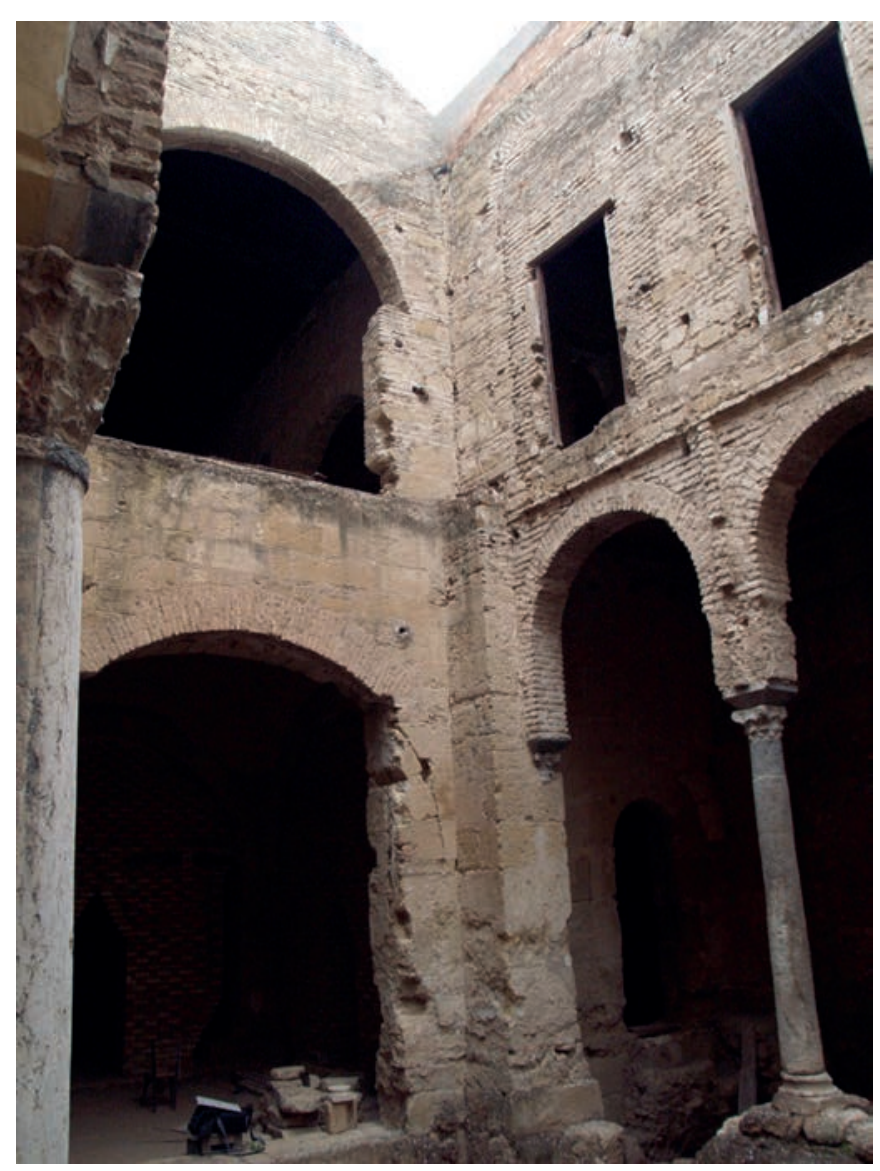

Figura 3. Iglesia de Santa Clara (Córdoba). Vista del patio interior.

La intención del Ayuntamiento de abrir el edificio para la visita pública en su estado actual ha sido el impulso inicial de este análisis. Por ello, el objetivo fundamental ha sido evaluar la posibilidad de retirada de los apeos existentes en las arquerías interiores del edificio y estimar el margen de seguridad en la actualidad para permitir la apertura al público. Además, se han propuesto las acciones necesarias para dotar a la estructura de la seguridad necesaria acorde a dicho uso público del edificio.

\section{METODOLOGÍA DE ANÁLISIS}

\section{Objetivos y organización de la metodología propuesta}

Como ya hemos indicado, nuestro objetivo es integrar el proceso de análisis patológico constructivo y estructural de los edificios históricos en el marco de su secuencia histórico-constructiva. De este modo, se presenta una fusión enriquecedora entre dos ámbitos que están íntimamente vinculados en la realidad material del edificio para ofrecer un soporte metodológico más adecuado dirigido al mejor conocimiento de nuestro patrimonio construido.

Además, pretendemos potenciar la colaboración interdisciplinar entre los distintos profesionales especialistas que intervienen en el estudio y conservación del patrimonio edificado (arqueólogos, arquitectos, historiadores, restauradores, etc.).

Esta propuesta se basa en la experiencia acumulada por los coautores del artículo, tanto en el análisis arqueológico de los edificios de orígenes y localizaciones diversas, como en el diagnóstico patológico de las estructuras históricas y la restauración de las mismas (Cámara y Latorre 2002, Cámara 2010). Todo ello nos ha permitido desarrollar una reflexión teórica conjunta para integrar los distintos enfoques en una herramienta de análisis que esperamos pueda servir como referencia y apoyo para otros especialistas en futuros trabajos.

El esquema organizativo de la metodología que presentamos se divide en una serie de fases de desarrollo:

1. Documentación gráfica

2. Análisis de la secuencia histórico-constructiva

3. Análisis de daños estructurales

4. Interpretación de la evolución histórica de la estructura

5. Cálculo estructural

6. Diagnóstico integrado

La característica fundamental radica en el hecho de combinar un análisis sincrónico del estado actual de la estructura con un análisis diacrónico, relativo a la evolución de la misma, para así obtener finalmente una visión de la historia de la estructura del edificio con sus 
procesos patológicos. De este modo, el análisis arqueológico y el análisis patológico se habrán combinado para obtener un diagnóstico integrado.

\section{Documentación gráfica}

El análisis que presentamos en este artículo, al igual que muchos otros trabajos de investigación, intervención o difusión que tienen como objeto el edificio histórico, debe contar con una adecuada documentación gráfica del mismo. Sin ser objeto del presente texto describir los métodos y técnicas de levantamiento y documentación gráfica (para más información, ver Martín 2014), sí consideramos oportuno especificar con claridad los requisitos que ésta debe cumplir para poder servir de base al análisis integrado que exponemos.

Como es bien sabido, la documentación gráfica de los edificios históricos cumple un doble objetivo. Por un lado, salvaguardar los valores culturales de los bienes culturales representados, de modo que a través del correcto levantamiento y dibujo arquitectónicos se registre tanto la geometría del edificio como sus elementos y técnicas constructivas (Fig. 4).

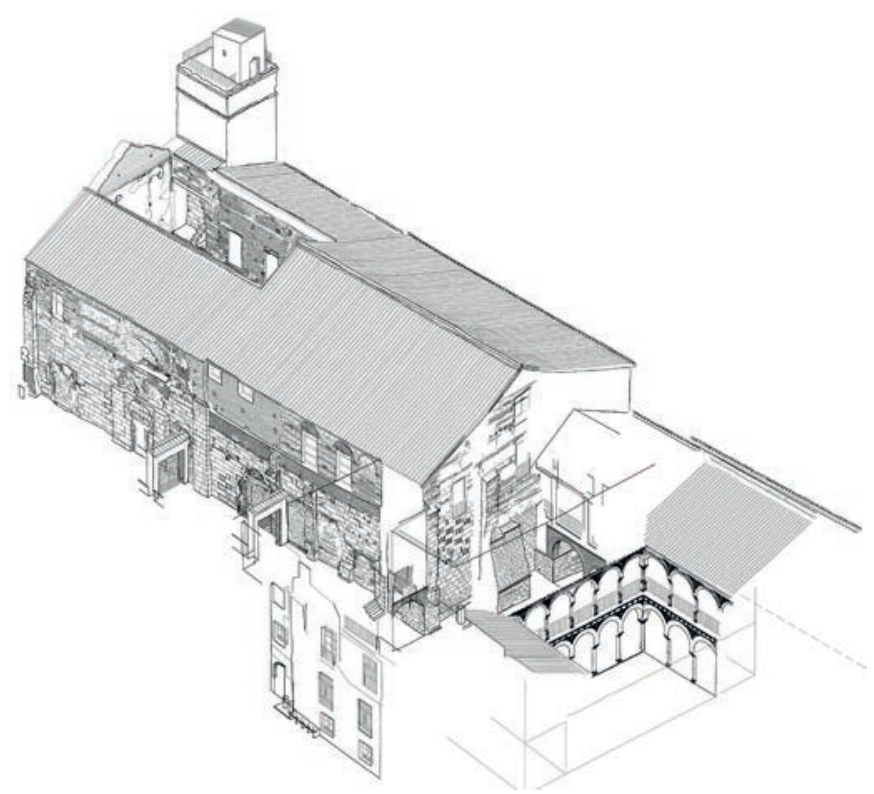

Figura 4. Modelo tridimensional fotogramétrico de la iglesia de Santa Clara.

Por otro lado, servir como herramienta fundamental para el desarrollo de otros trabajos relacionados con el estudio, la conservación o la difusión del patrimonio edificado. Para ello, la documentación gráfica debe cumplir unos requisitos en función de las necesidades de dichos trabajos. En el caso que nos ocupa, las necesidades del análisis estratigráfico y del estudio patológico establecen los siguientes requisitos para la documentación gráfica:

- Incluir una representación tridimensional (modelo 3D) así como un completo juego de planimetrías bidimensionales (dibujos de plantas, alzados y secciones) que abarquen la totalidad del objeto de estudio, tanto por su exterior como por su interior.

- Registrar la geometría del edificio con sus deformaciones, desviaciones, asimetrías y otras irregularidades sin simplificarla en exceso, ya que estos aspectos pueden ser clave para el posterior desarrollo del análisis.

- Documentar a través del dibujo los elementos constructivos con un adecuado nivel de detalle, incluyendo despieces, revestimientos, encuentros singulares, etc.

El proceso de toma de datos y dibujo de la documentación gráfica conlleva intrínsecamente un primer análisis geométrico-constructivo y, por lo tanto, es en todos los casos un proceso de interpretación subjetiva, donde la experiencia y conocimiento del autor son fundamentales para alcanzar una buena calidad de la misma (Fig. 5).

\section{Análisis de la secuencia histórico- constructiva}

El estudio de la secuencia evolutiva del edificio histórico se basa en el marco metodológico de la Arqueología de la Arquitectura. Sin entrar a detallar esta metodología, ya que excede el objetivo de este artículo, sí conviene señalar que a través de su aplicación el edificio histórico se convierte en un documento legible. De forma sintética podemos decir que existen cuatro estrategias principales (Caballero 2010: 107-115): la estratigrafía, que permite identificar las sucesivas UE menores divisibles que componen un complejo arqueológico (yacimiento o edificio) y ordenarlas en una secuencia relativa; la tipología, con la que caracterizar las características de esas UE y tipificarlas; los registros escritos, que permiten contextualizar las actividades que sucedieron en la construcción y sus efectos; y, cuando es necesario, la arqueometría, con la que caracterizar y ofrecer acercamientos cronológicos de los materiales (cerámica, madera...) empleados en el edificio con la ayuda de exámenes físicos y químicos (Fig. 6). 


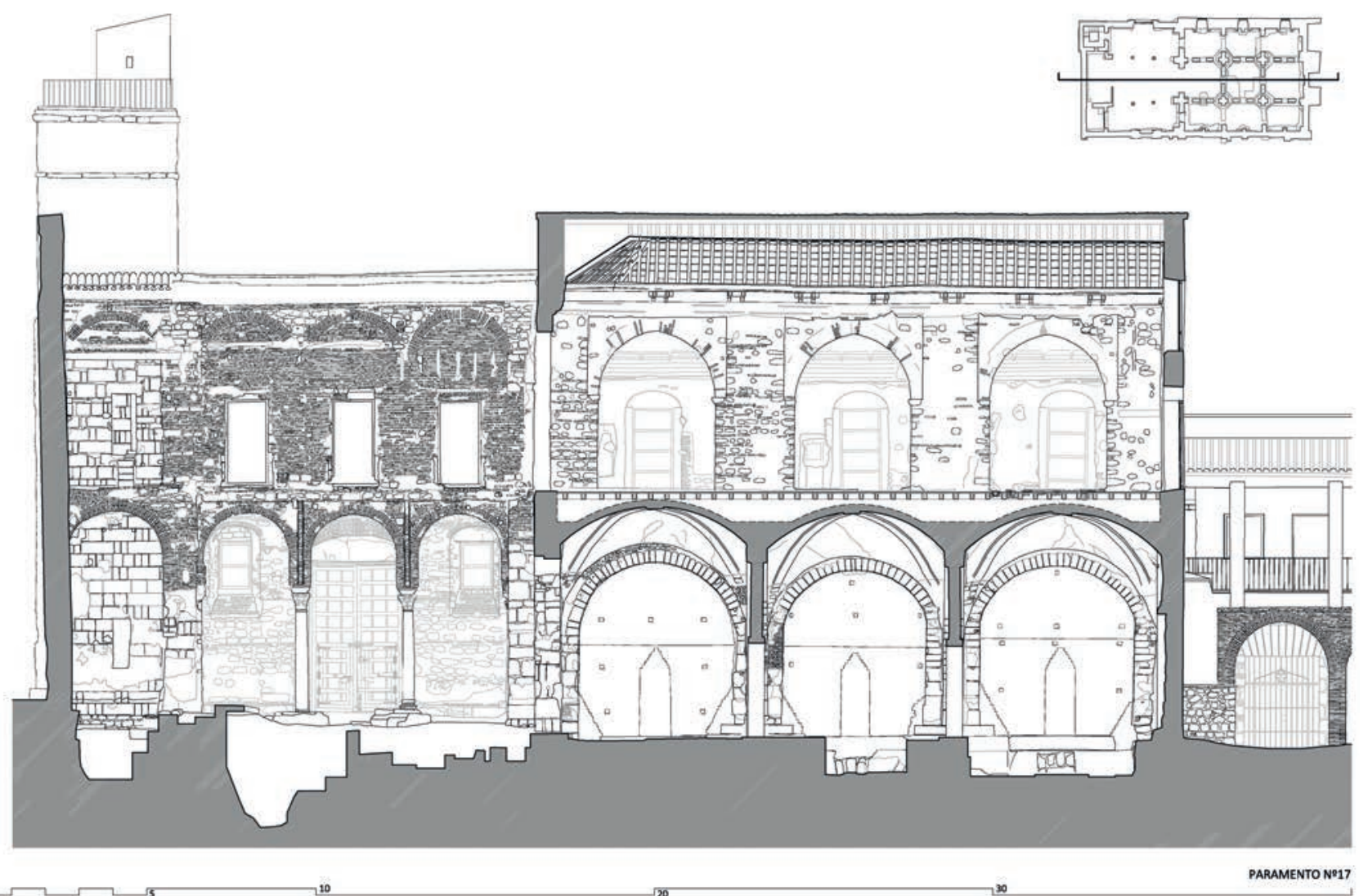

Figura 5. Sección longitudinal de la iglesia de Santa Clara.
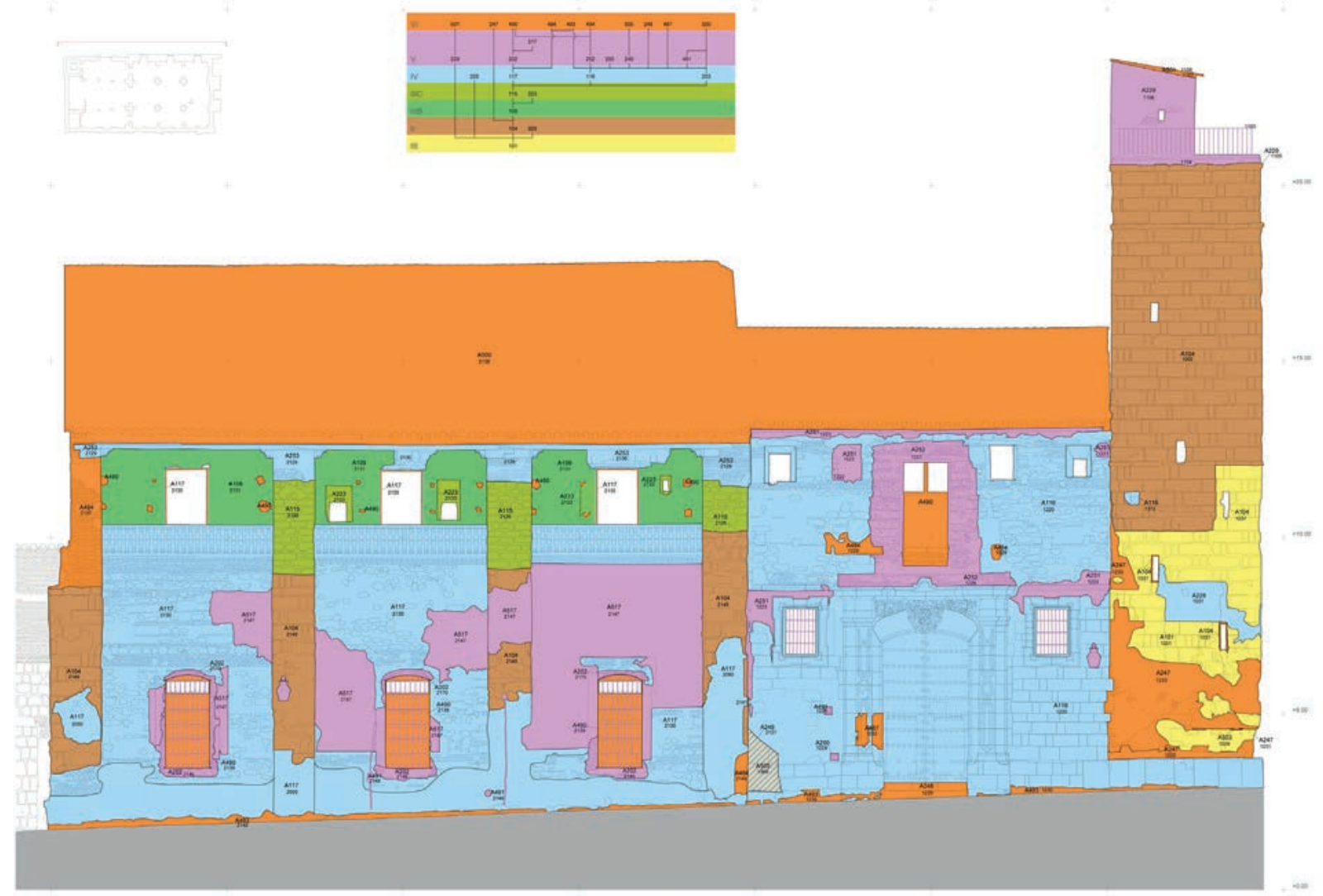

Figura 6. Fachada noreste de la iglesia de Santa Clara. 
Puesto que la metodología propuesta se basa en una integración interdisciplinar de dos perspectivas complementarias, ya durante el desarrollo del análisis arqueológico (lectura de paramentos) el equipo debe centrarse también en la identificación de las lesiones existentes y en su contextualización en la secuencia histórico-constructiva, de modo que se entiendan las transformaciones del edificio no sólo desde el uso y la funcionalidad del mismo, sino también desde la óptica de su repercusión en la estructura y en los procesos patológicos que sufre a lo largo de su historia.

Por ello, durante la lectura de paramentos también se han de inspeccionar desde un punto de vista estratigráfico las distintas lesiones existentes. Brogiolo y Cagnana (2012: 47-49, 56-57; introducido en Brogiolo 2010) recogen la necesidad de tomar en consideración como elementos estratigráficos describibles dentro de la secuencia estructural del edificio aspectos sobre equilibrio, inestabilidad y degradación, que consideran son el resultado de una actividad postdeposicional. Para la definición de este aspecto introducen el concepto de "secuencia de la degradación" que contempla como unidad estratigráfica muraria negativa aquellas deformaciones funcionales y geométricas resultado de una fisura, grieta, ruina o una demolición más aquellas alteraciones provocadas por la acción de agentes físico-químicos.

De este modo, se deben identificar las deformaciones y roturas en todos aquellos elementos significativos desde el punto de vista de la patología estructural, incluyendo los revestimientos y otros elementos superficiales. En términos generales, podemos decir que la estructura sufre movimientos que provocan deformaciones. Sin ánimo de detallar un exhaustivo catálogo de lesiones patológicas, sí conviene indicar los principales movimientos y sus deformaciones asociadas.

Por un lado, es frecuente encontrar giros de algunos de los elementos constructivos (generalmente muros o pilares). Los giros más comunes se producen en un plano vertical, de modo que mediante una rotación con centro en la base de los muros o pilares, producen un desplome en su cabeza ${ }^{4}$ (Fig. 7). También se pueden dar giros en planos horizontales, que usualmente provocan torsiones y deformaciones complejas, sobre todo en los pilares y otros elementos esbeltos.

\footnotetext{
4 Este desplome, estrictamente hablando, es un giro del elemento, aunque para simplificar el proceso lo consideraremos como un movimiento horizontal en el sentido que indique el giro.
}

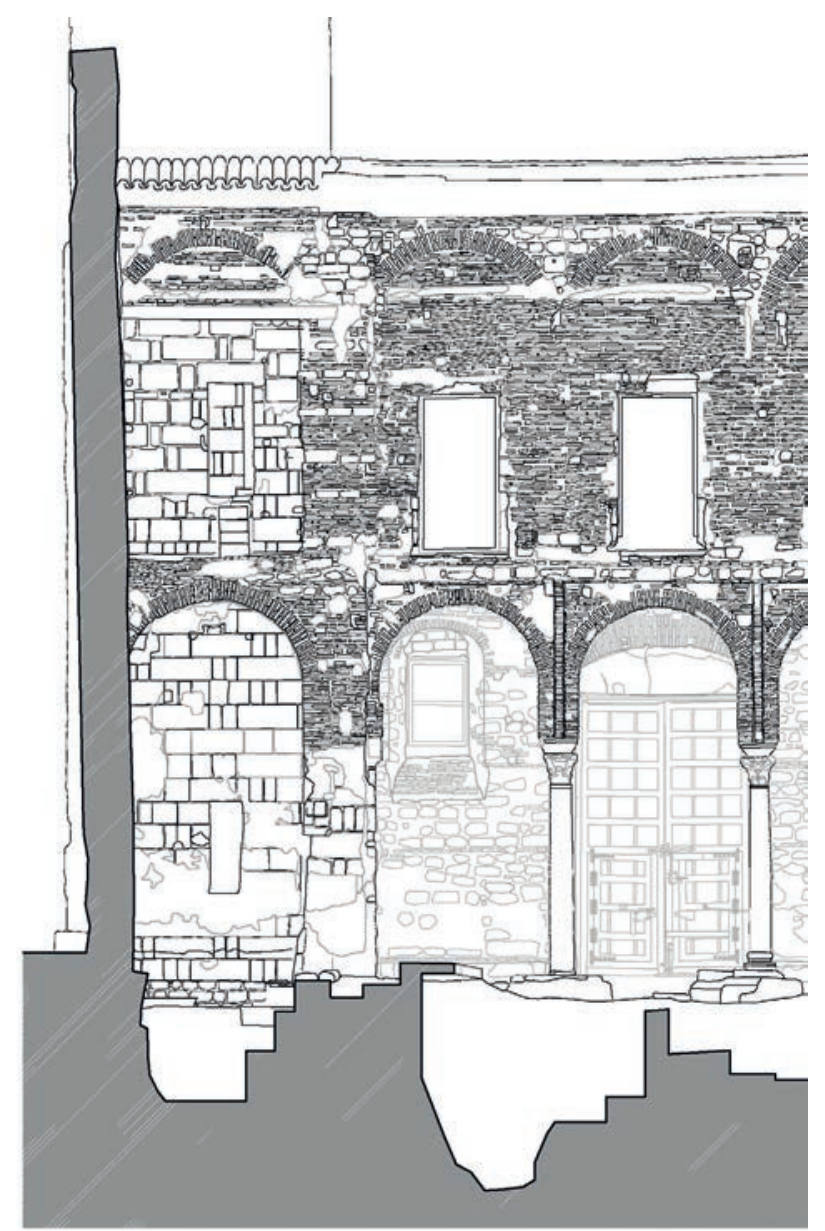

Figura 7. Desplome del muro nordeste de la iglesia de Santa Clara.

Por otro lado, el apoyo del edificio en el terreno puede provocar asientos en el mismo. Contrariamente al uso habitual del término, un asiento no es sencillamente un descenso de la cimentación porque el terreno haya cedido. Es necesario entender que el proceso de consolidación del terreno para adaptarse a las cargas que le transmite el edificio es un proceso largo, continúo y que afecta a toda la superficie bajo y alrededor de la construcción. Por ello, podemos considerar que el descenso de la misma durante esta consolidación es paulatino y generalizado en toda su extensión, y que en principio no supone un problema para la estabilidad de la estructura. Sin embargo, sí pueden producirse problemas estructurales cuando existen diferencias significativas en la velocidad de asiento de unos puntos de la edificación respecto de otros, ya que ello provoca descensos relativos distintos y una alteración importante de la geometría de los apoyos de la estructura (Fig. 8). Es lo que llamamos asiento diferencial, y produce deformaciones fundamentalmente en los elementos de conexión entre los puntos con descensos relativos distintos (arcos, bóvedas, vigas, forjados, etc.). 


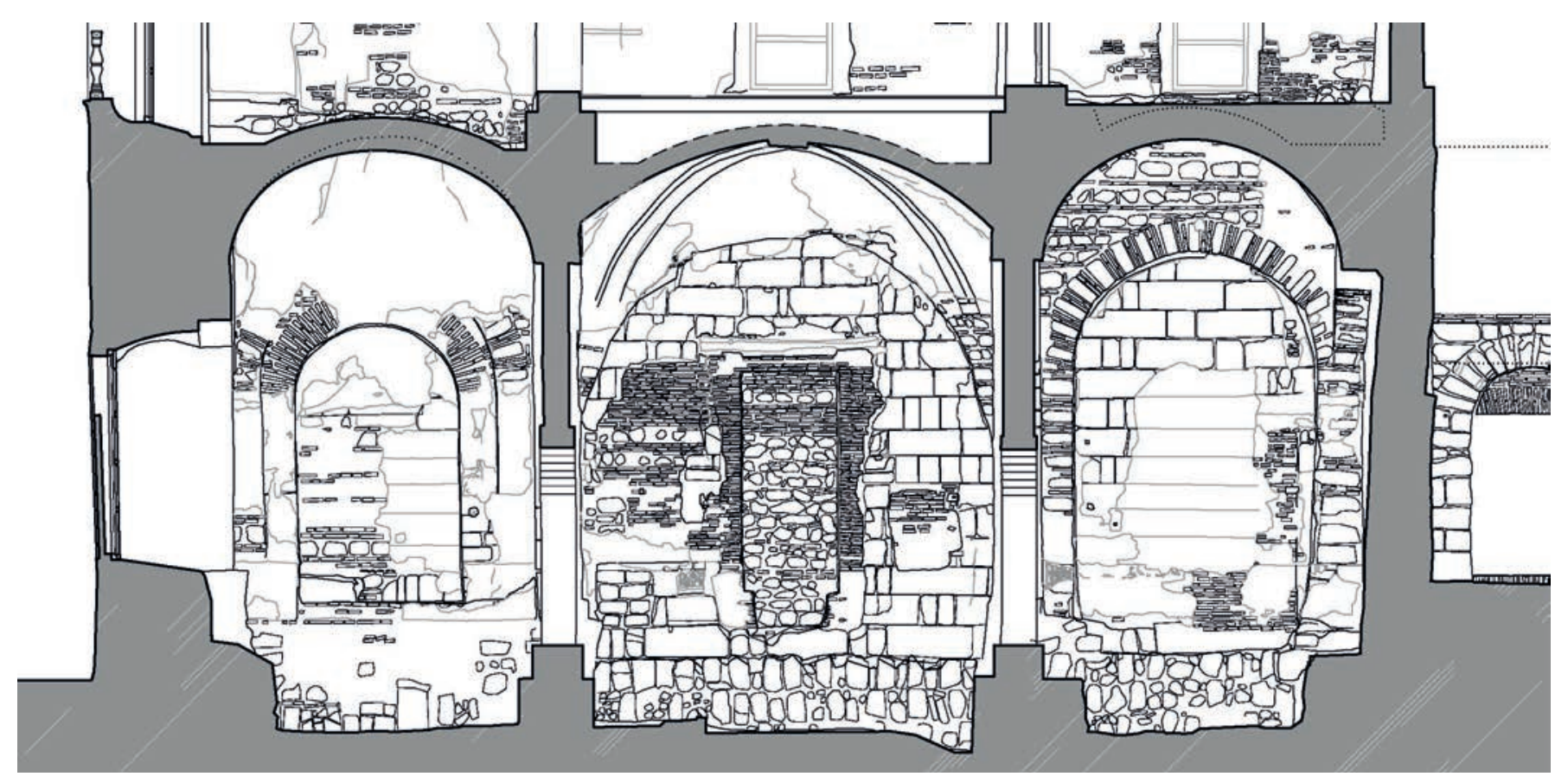

Figura 8. Desplomes, asientos diferenciales y deformaciones en la planta baja de la iglesia de Santa Clara.

Las deformaciones anteriormente mencionadas provocan tensiones adicionales de compresión en unos puntos y tracción en otros, y deben ser absorbidas por la estructura para mantenerse en equilibrio. Puesto que las construcciones de fábrica tienen una elevada resistencia a la compresión, este tipo de tensiones no suelen afectar significativamente a los materiales. Sin embargo, dado que poseen una muy reducida resistencia a la tracción (podemos considerarla nula), este tipo de esfuerzos sólo pueden ser asumidos por la estructura mediante su rotura parcial, apareciendo fisuras y $\operatorname{grietas}^{5}$ (Fig. 9). Este tipo de lesiones no tienen por qué revestir a priori riesgo alguno, sino que son la respuesta natural que la estructura tiene para adaptarse a las deformaciones que sufre.

De este modo, una vez identificadas visualmente las lesiones, se registrarán mediante fotografías y su dibujo en la planimetría del edificio con su correspondiente código identificativo y acompañadas de la magnitud asociada, cuando sea posible obtenerla, mediante la medición directa en el edificio o en su representación gráfica tridimensional ${ }^{6}$. En el caso de las grietas, cuando

\footnotetext{
5 Entendemos por fisuras o grietas las roturas de los materiales constructivos; mientras que las primeras afectan por lo general a capas superficiales (revestimientos o acabados), las segundas tienen mayor entidad y atraviesan los elementos constructivos en una parte importante de su espesor.

6 La medición directa suele ser imposible de obtener en muchas partes del edificio, de ahí la importancia de contar con un modelo tridimensional adecuado que no simplifique la geometría de la construcción.
}

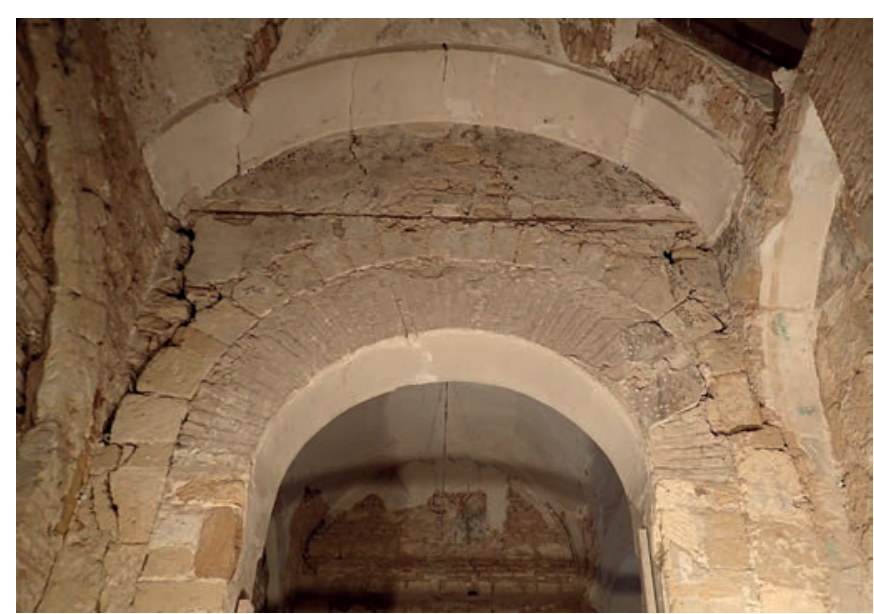

Figura 9. Grietas entre las dovelas de uno de los arcos de la iglesia de Santa Clara.

sea posible, se obtendrá la magnitud de su apertura, indicándose también el sentido en el que progresan. Se debe mantener una coherencia con la división del edificio en sus distintas etapas históricas, de modo que la toma de datos de desplomes u otras deformaciones se fragmente de igual manera, adecuándose a la realidad pluriestratigráfica del edificio histórico. Así la medición y registro se realizará sobre partes o bloques asociados a una misma etapa histórica para no generar datos incongruentes (Fig 10). 


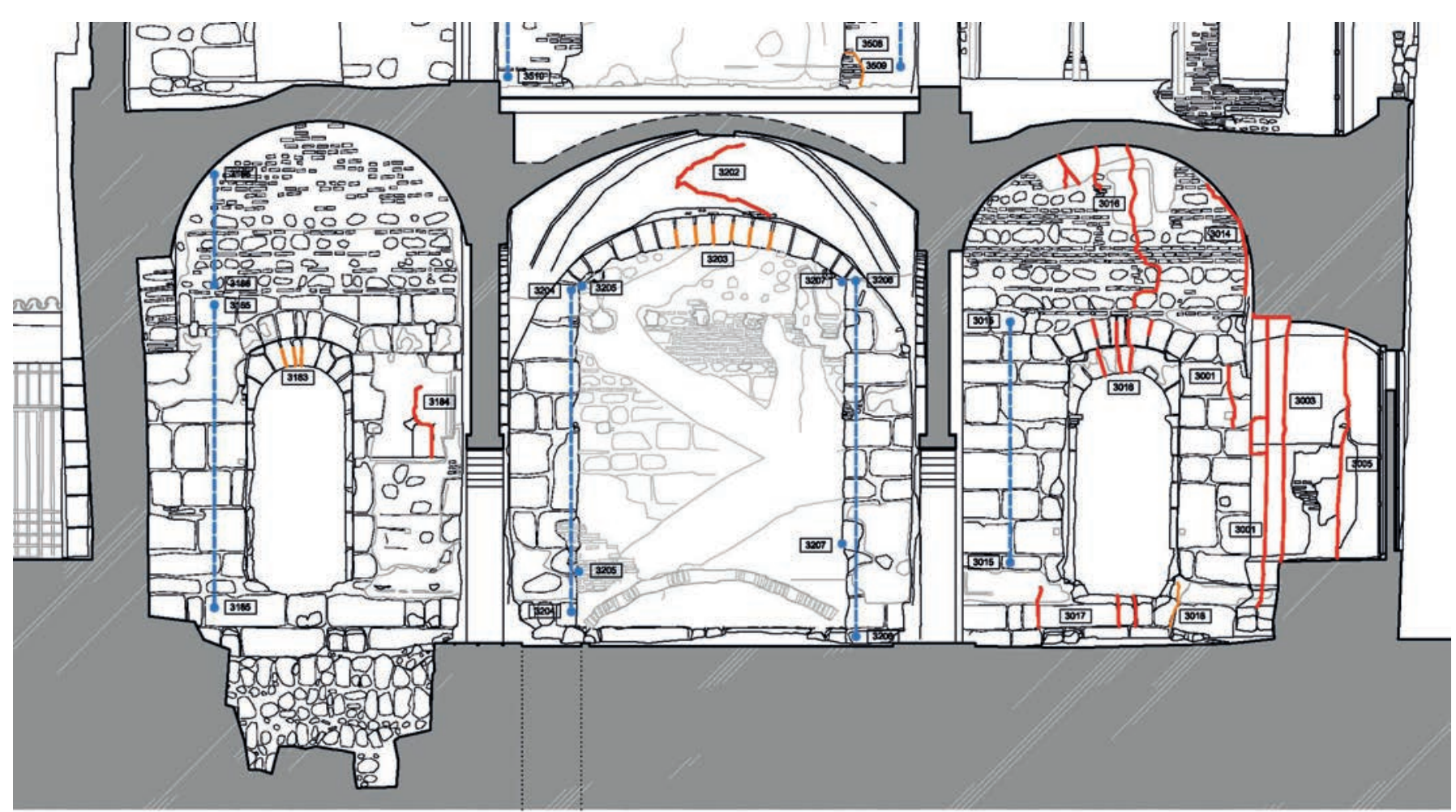

Figura 10. Registro e identificación de lesiones (grietas y desplomes).

Finalmente, se registrarán los distintos elementos constructivos que presenten pérdidas, alteraciones, ataques biológicos o cualquier otro tipo de lesión que pueda comprometer su seguridad estructural ${ }^{7}$.

\section{Análisis de daños estructurales}

Una vez identificadas y registradas las principales lesiones en el edificio, se debe proceder a su análisis en un doble sentido. Por un lado, deduciendo las causas que las producen y, por otro, estudiando el estado actual activo o detenido de las mismas. Ello permite obtener una primera visión global del estado estructural y constructivo del edificio.

Cada una de las lesiones de la estructura (deformaciones o agrietamientos) responde a un proceso patológico (por ejemplo, un movimiento de las fábricas) que las provoca, de modo que movimiento y lesión están íntimamente vinculados. Hablamos de un proceso inactivo cuando está completamente detenido en el momento actual, de modo que, aunque en el pasado haya

\footnotetext{
7 Además del registro de lesiones, se han de analizar en detalle las distintas soluciones constructivas que configuran el edificio, especialmente los encuentros de unos sistemas constructivos con otros (apoyos de forjados en muros, encuentros de bóvedas con muros, apoyos de muros, etc.).
}

afectado a la estructura, hoy en día no tiene repercusión alguna. Por el contrario, los procesos activos son aquellos que de algún modo siguen vivos y pueden condicionar el estado de equilibrio de la estructura. En este tipo de situaciones podemos distinguir dos tipos. Por un lado, pueden ser procesos activos progresivos, es decir, aquellos que avanzan en un sentido único, aumentando progresivamente la magnitud de sus efectos, por ejemplo, un movimiento que causa una deformación cada vez mayor. Por otro lado, puede tratarse de procesos activos cíclicos, es decir, aquellos que alternativamente avanzan y retroceden según unos determinados ciclos, por ejemplo, los movimientos de dilatación y contracción que se producen en los edificios por el aumento y la disminución de las temperaturas en cada ciclo anual. Este tipo de procesos cíclicos no tienen por qué retornar siempre al mismo punto de partida, de modo que se pueden acumular efectos residuales que resultan de la variación relativa entre un ciclo y otro. El método que proponemos usa el propio edificio como testigo de sus propios procesos patológicos, de modo que nos permite interpretar qué tipo de procesos se desarrollan. De este modo, a partir de las lesiones observadas, deben deducirse los movimientos individuales que las producen en base a la lógica mecánica de este tipo de estructuras. 
El hecho de que los edificios históricos tengan un carácter pluriestratigráfico conlleva la separación de sus fábricas en fases constructivas, la cual ha podido ser obtenida mediante el análisis estratigráfico. Además, las grietas existentes nos indican otro nivel de división interna de las estructuras que, aunque puedan tener un origen coetáneo, hoy en día están parcial o totalmente separadas. Estas interfaces (soluciones de continuidad entre fases constructivas y cortes producidos por las grietas) permiten establecer una división del edificio en un conjunto de bloques relativamente independientes entre ellos que será fundamental para entender el comportamiento estructural con mayor rigor. Introducimos así la noción de "bloque" de construcción como la parte de ésta que se mueve sin fracturarse, como una pieza monolítica $\multimap$ casi-, que se separa de otras piezas similares que se mueven de distinta manera o quedan aparentemente inmóviles. Las grietas entre partes de la estructura serán las "juntas" entre bloques, y nos indicarán por su forma qué se ha movido respecto a qué (Fig. 11).

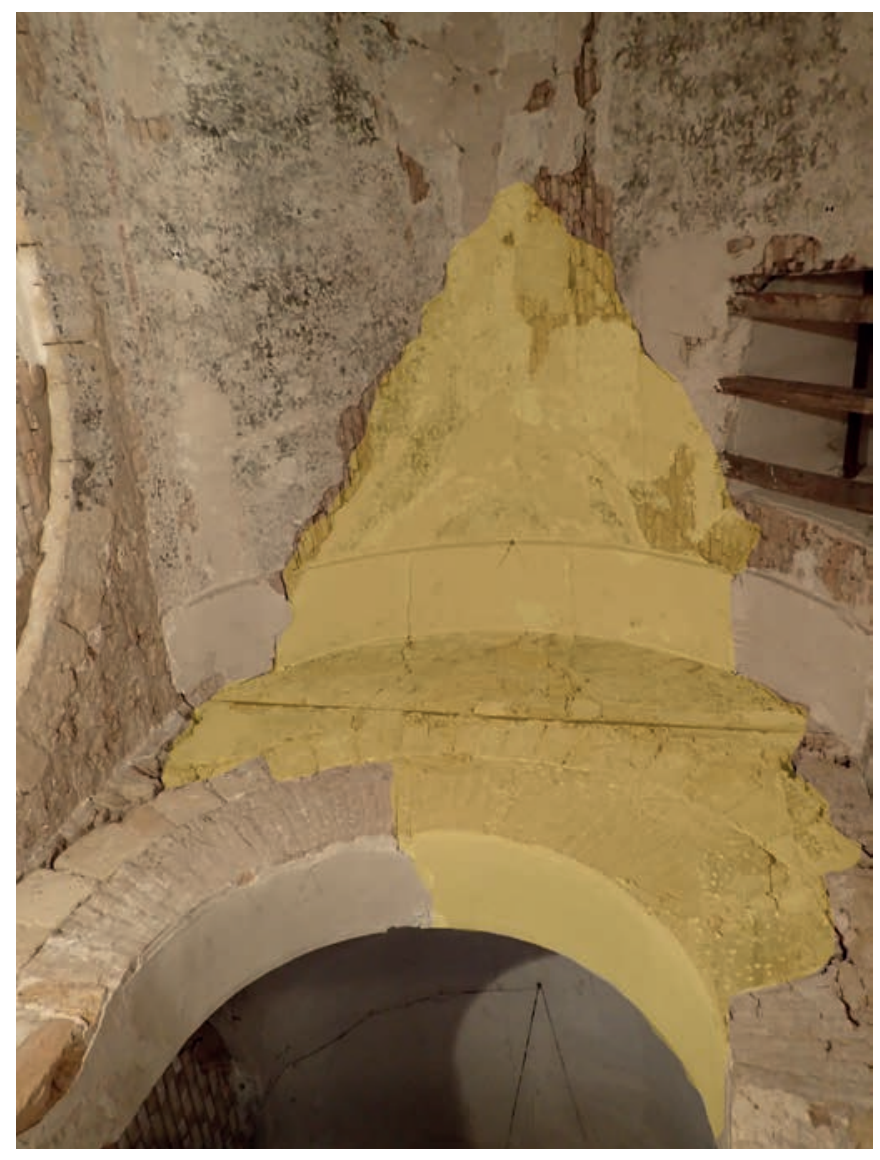

Figura 11. Formación de bloque en arco y bóveda mediante grietas.

En definitiva, podemos establecer tres niveles de división de los edificios. El mayor, corresponde a los propios elementos constructivos (muros, pilares, arcos, bóvedas, etc.), que tienen una entidad independiente desde el momento de su ejecución. Cada uno de ellos puede a su vez subdividirse en varias fases constructivas, quedando separados por las soluciones de continuidad correspondientes (por ejemplo, las distintas partes de un muro que se construyen en distintas etapas históricas). Finalmente, las roturas producidas por las deformaciones crean nuevas divisiones internas que separan unas partes de otras según la lógica de la mecánica estructural (por ejemplo, un trozo de muro que se separa de otro al agrietarse). De este modo, los "bloques" serán las UE mínimas materiales fruto de la fragmentación combinada en los tres niveles anteriormente mencionados y configuran la base fundamental del análisis de la estructura.

El proceso de análisis de los daños estructurales realizado parte de la consideración del cuerpo edificado como un conjunto de masas en equilibrio "evolutivo", es decir, no plenamente estático. Esta "evolución" de la estructura tiene que ver con distintas variables. En primer lugar, las cuestiones relacionadas con el desarrollo del asiento diferencial y progresivo del terreno y, en segundo lugar, los cambios en la propia configuración constructiva y funcional del edificio, que modifican cargas y elementos resistentes. Esa apreciación del edificio como una estructura en movimiento y cambio no es una mera cuestión teórica, sino que es la variable que resulta realmente importante analizar para evaluar la seguridad de la estructura. En efecto, puesto que no hay posibilidad de detener ninguno de los dos procesos (el de asiento del terreno y el de sucesión de usos por el otro), es necesario tratar de averiguar qué camino se ha recorrido y hacia dónde parece evolucionar la estructura para ponderar los márgenes residuales de movimiento que le quedan antes de llegar a una posible ruina.

El proceso de análisis incluirá por lo tanto la detección y caracterización de los movimientos de las fábricas a partir de los desplomes y de la localización de grietas. Señalados todos ellos se puede hacer una hipótesis de cuál ha sido el comportamiento "evolutivo" de la estructura, es decir, qué partes se han movido hacia dónde y en qué magnitud. Esos movimientos nos indicarán su origen al quedar delatados por la aparición de grietas en las fábricas, que no son otra cosa que las huellas de la separación entre distintos bloques de edificación. Llegados a este punto, tendremos identificados e individualizados los elementos básicos del análisis: las lesiones (fundamentalmente deformaciones y grietas), los movimientos que las producen y los bloques en que se divide la estructura (Fig. 12). 


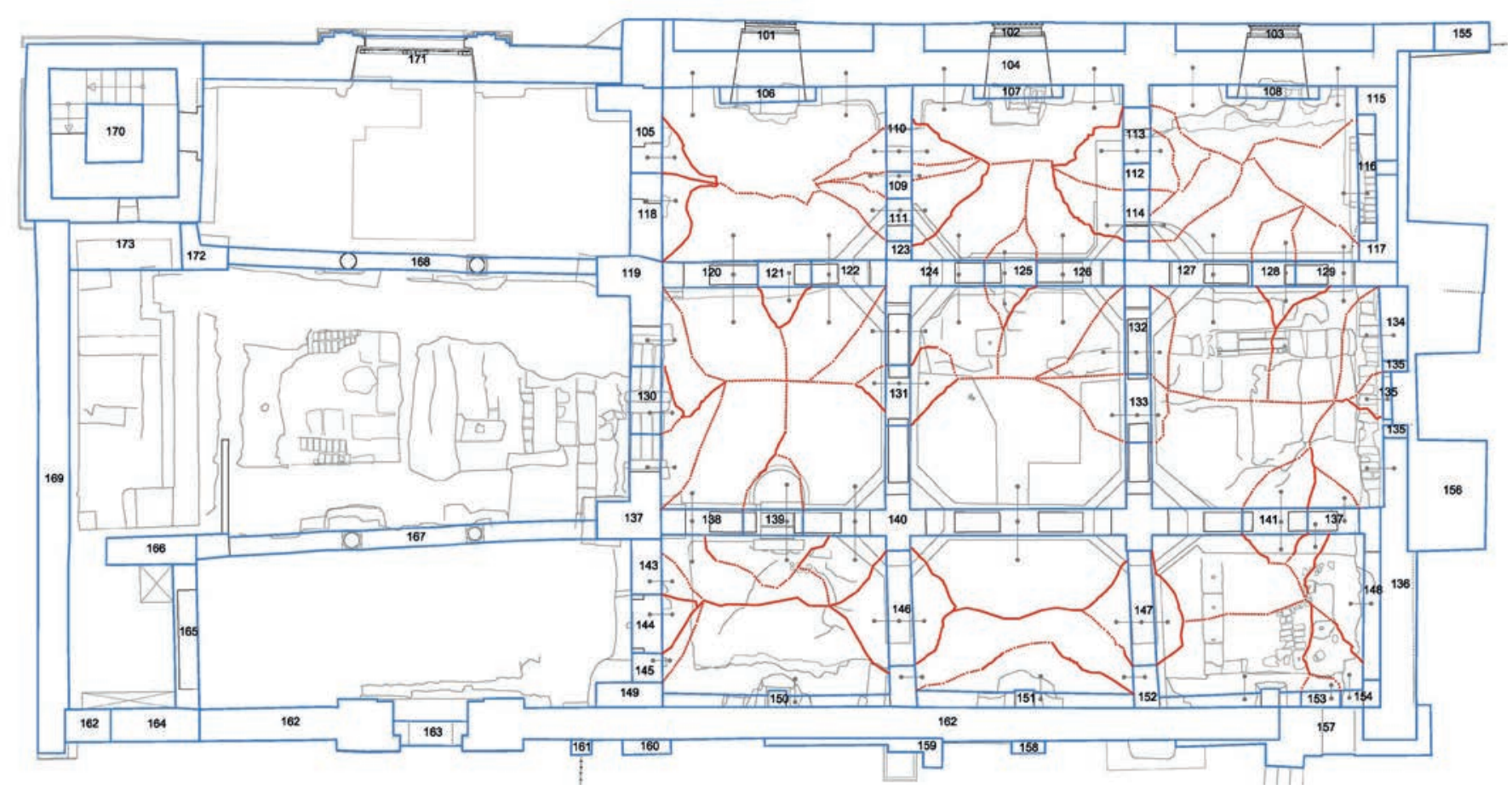

Figura 12. Bloques identificados en la planta baja de la iglesia de Santa Clara.

Interpretación de la evolución histórica de la estructura

Una de las grandes innovaciones de la metodología que se propone es precisamente abordar el estudio de la estructura desde una perspectiva diacrónica, analizando sus procesos patológicos con una perspectiva evolutiva mediante la integración con el análisis estratigráfico. En esta fase del análisis se tratará por lo tanto de conectar la secuencia de actuaciones históricas con los movimientos de la estructura a lo largo del tiempo.

Como es bien conocido, la metodología arqueológica de análisis estratigráfico comienza con la descomposición del objeto de estudio en sus unidades estratigráficas (UE). En el ejercicio conceptual de integración del análisis patológico, podemos considerar las lesiones individuales (grietas, desplomes, etc.) como UE de tipo interfacial. Dichas lesiones son UE fundamentales que expresan las consecuencias de los procesos patológicos.

Seguidamente, la lectura arqueológica aborda una fase de síntesis en actividades periodizadas mediante una labor de reducción y correlación. Del mismo modo, durante el análisis de las lesiones, se sigue un proceso de síntesis, primero identificando los bloques en los que se divide la construcción por efecto bien de sus transformaciones por cambio de usos o bien de sus procesos patológicos. Por lo tanto, las lesiones individuales junto con las soluciones constructivas derivadas de las transformaciones forman los bloques, que se relacionan directamente con movimientos individualizados de los distintos elementos constructivos. Podemos establecer una analogía entre el concepto de "actividad" en la secuencia estratigráfica con el de "movimiento" de la estructura. Del mismo modo que una actividad engloba todas aquellas UE que tienen una misma finalidad constructiva, los movimientos son los responsables de provocar un conjunto determinado de lesiones que tienen en común la definición de un bloque que se separa e individualiza del resto de la construcción.

Finalmente, la metodología arqueológica establece un siguiente nivel de síntesis que consiste en la agrupación de varias actividades en una determinada fase constructiva, que generalmente se puede asociar a un periodo histórico determinado. En el proceso de integración del análisis patológico, también es necesario sintetizar el conjunto de movimientos individuales de la estructura en un nivel superior que podemos denominar "grandes desplazamientos", que vienen a ser los principales movimientos que sufre el conjunto de la construcción. Estos grandes desplazamientos agrupan conjuntos de los mencionados movimientos individuales que tienen una direccionalidad y unas pautas mecánicas comunes. Sin embargo, los grandes desplazamientos no tienen por qué quedar circunscritos 
a un determinado periodo histórico, siendo generalmente transversales o diacrónicos a la división temporal.

Para desarrollar este proceso de síntesis, el análisis arqueológico se apoya en la confección de un diagrama completo, o matriz de Harris (1979), sin relaciones redundantes, ordenado por etapas. Su manejo permite el control y revisión de la argumentación analítica y aporta la cuarta dimensión, el tiempo, a la lectura del objeto material en la tercera dimensión, el espacio. También en este caso se deben integrar las lesiones, movimientos o grandes desplazamientos en el diagrama estratigráfico, en función de si ésta representa las UE, actividades o fases. De este modo, se ponen en relación los movimientos con las actividades y fases históricas reflejadas en el diagrama estratigráfico, de manera que se dilucida a cuáles de estas actividades y fases afectan los movimientos considerados. Sin embargo, no es una tarea fácil secuenciar con precisión el momento en el que se producen los daños. Sólo conocemos su evidente posterioridad al momento que corresponde el elemento afectado y por lo tanto proponemos secuenciarlos a continuación, recogiéndolo de este modo en el diagrama (Fig. 13).

Como se puede observar en el diagrama, los elementos materiales de la construcción (unidades positivas) quedan adscritos a un único periodo histórico. Sin embargo, algunos movimientos y las lesiones que producen (las cuales son de tipo interfacial o unidades negativas) aparecen en distintas etapas de la historia. Se trata por lo tanto de elementos diacrónicos que "ascienden" por el diagrama. Esto se explica por el hecho de que un movimiento puede ocasionarse en un momento concreto y permanecer activo a lo largo de varias etapas hasta que, bien se detiene, bien sigue activo en la actualidad. En definitiva, nos encontramos ante una clara justificación de la consideración del cuerpo edificado como un conjunto de masas en equilibrio "evolutivo".

El resultado del estudio debe establecer qué movimientos se encuentran detenidos y desde qué momento, en función de a qué etapas históricas afecta y a cuáles, posteriores a esas, no lo hace. Se entiende entonces que ese movimiento ha estado activo entre las primeras etapas (las que estarían afectadas por el movimiento) y las últimas (no afectadas), si es que existen éstas. En este caso, podremos deducir que a partir del momento en que se realiza la actividad no afectada por el movimiento, éste ha debido quedar detenido: esa actividad "cancela" el movimiento, lo sella temporalmente y nos aporta el indicio de que esa parte de la obra ha quedado estabilizada desde ese momento.

De este modo, conseguimos completar la secuencia histórico-constructiva por medio del análisis estructural, con el rigor del diagrama estratigráfico y de haber identificado sobre el propio edificio las UE o actividades afectadas por cada movimiento. Además, permite identificar la evolución temporal de los movimientos a lo largo de la historia del edificio (su velocidad y aceleración o ralentizamiento) $\mathrm{y}$, lo que es más importante, detectar aquellos movimientos activos en el momento actual, ya que no han sido cancelados por ninguna actividad constructiva. Estos procesos activos serán los que requerirán la mayor atención de cara a la intervención en el edificio, por lo que esta metodología integrada es una ayuda muy importante para detectarlos, evaluar los riesgos y los márgenes de seguridad, así como focalizar correctamente los esfuerzos en la intervención.

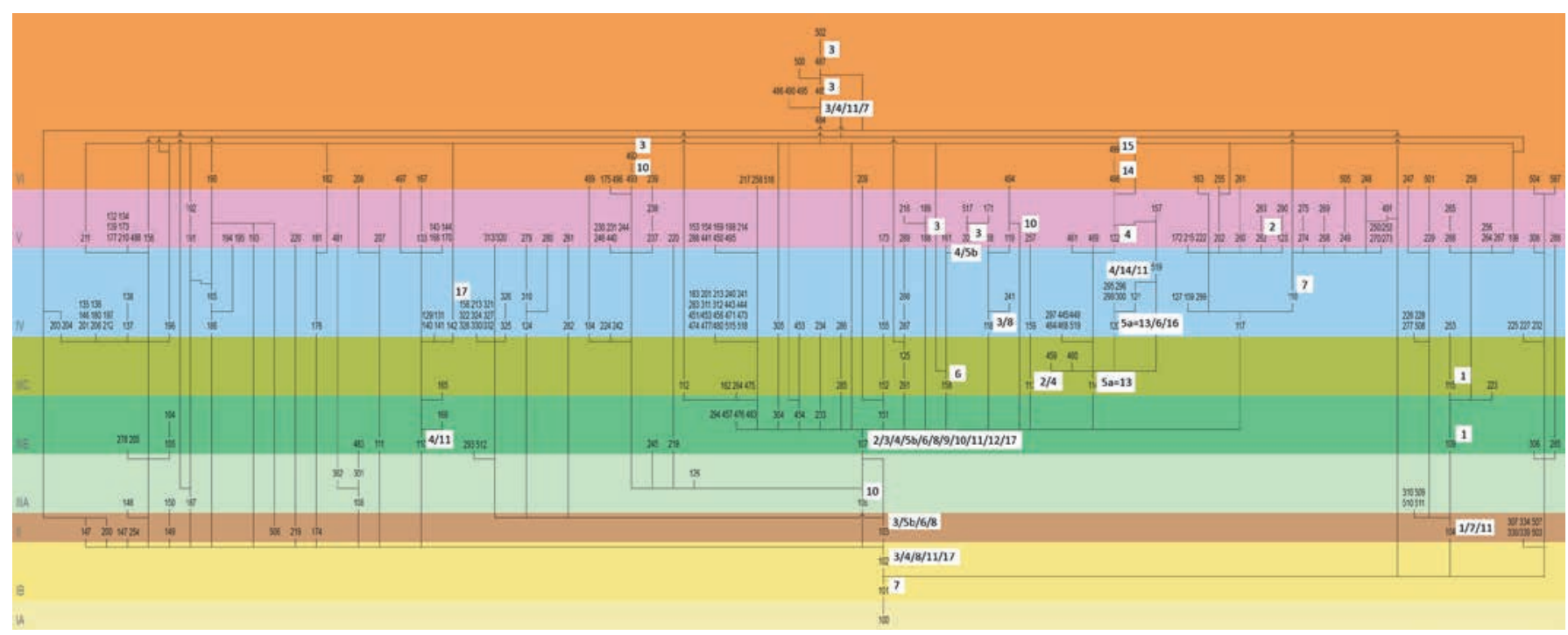

Figura 13. Diagrama estratigráfico resultante de la lectura arqueológica con los "grandes movimientos" integrados y marcados con fondo en blanco. 


\section{Cálculo estructural}

Complementariamente a la visión diacrónica o evolutiva de la estructura, será necesario realizar un análisis sincrónico del estado actual. Es decir, realizar un cálculo de los estados de equilibrios del edificio para determinar los mecanismos de colapso y los márgenes de seguridad existente. Aunque la metodología de cálculo no es objeto de desarrollo en este artículo, sí es necesario señalar que es fundamental que dicho método sea coherente con la naturaleza del edificio histórico. Gran parte de los análisis estructurales realizados hoy en día se basan en métodos desarrollados para sistemas constructivos y materiales contemporáneos que son sin embargo aplicados directamente a las construcciones históricas, sin tener en cuenta que sus principios mecánicos y características son distintos.

Por ello, entendemos que para abordar este tipo de cálculos debe tomarse como marco teórico el del análisis límite y de la seguridad de las fábricas enunciadas por Jacques Heyman (1999) desarrollándose mediante la aplicación de la estática gráfica tridimensional basada en la documentación gráfica existente. Las premisas que se asumen en este tipo de análisis son distintas de los cálculos estructurales realizados sobre edificios de nueva planta, ya que tienen en cuenta las características constructivas y mecánicas de los materiales históricos, claramente distintas de los actuales (Fig. 14).

\section{Diagnóstico integrado}

La visión conjunta de los enfoques descritos, comparando la perspectiva diacrónica y sincrónica, permitirá obtener un verdadero diagnóstico integrado, que entendemos es el único modo de comprender en profundidad tanto la evolución histórico-constructiva como la patológico-estructural del edificio a lo largo de su historia, detectar adecuadamente las causas de los procesos patológicos y evaluar el margen de seguridad y el riesgo de colapso. Este diagnóstico integrado será sin duda el mejor soporte para la toma de decisiones eficientes para la conservación del patrimonio construido.

\section{EL CASO DE LA IGLESIA DE SANTA CLARA EN CÓRDOBA}

\section{Análisis de la secuencia histórico-constructiva}

\section{Secuencia histórico-constructiva de la iglesia del convento de Santa Clara}

La aplicación del modelo de análisis de la Arqueología de la Arquitectura llevada a cabo en Santa Clara permite secuenciar sus estructuras en 6 etapas generales. La última corresponde al periodo de restauración (Figs. 15 y 16). A continuación presentamos una resumida síntesis

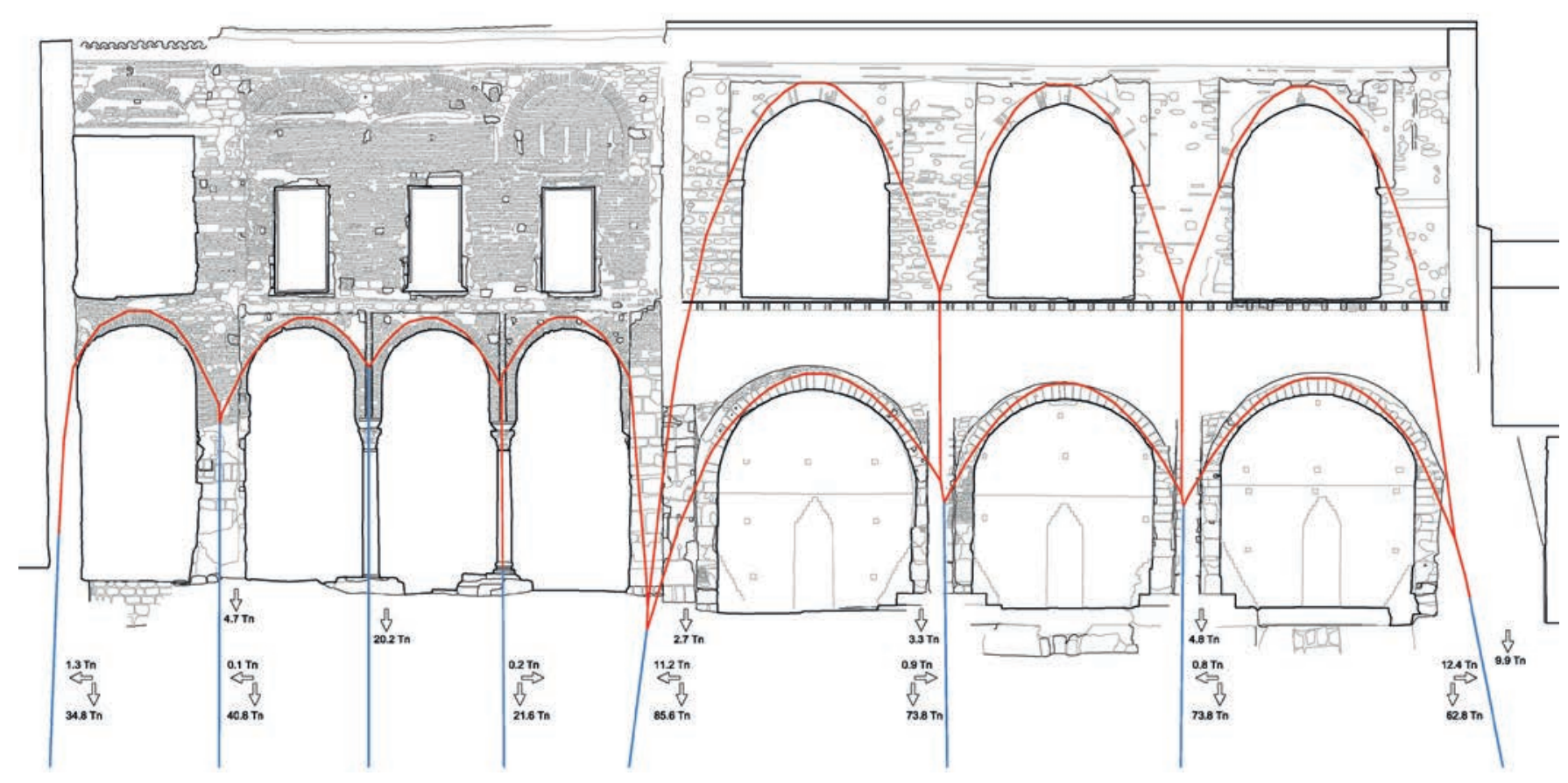

Figura 14. Cálculo de líneas de empujes. 


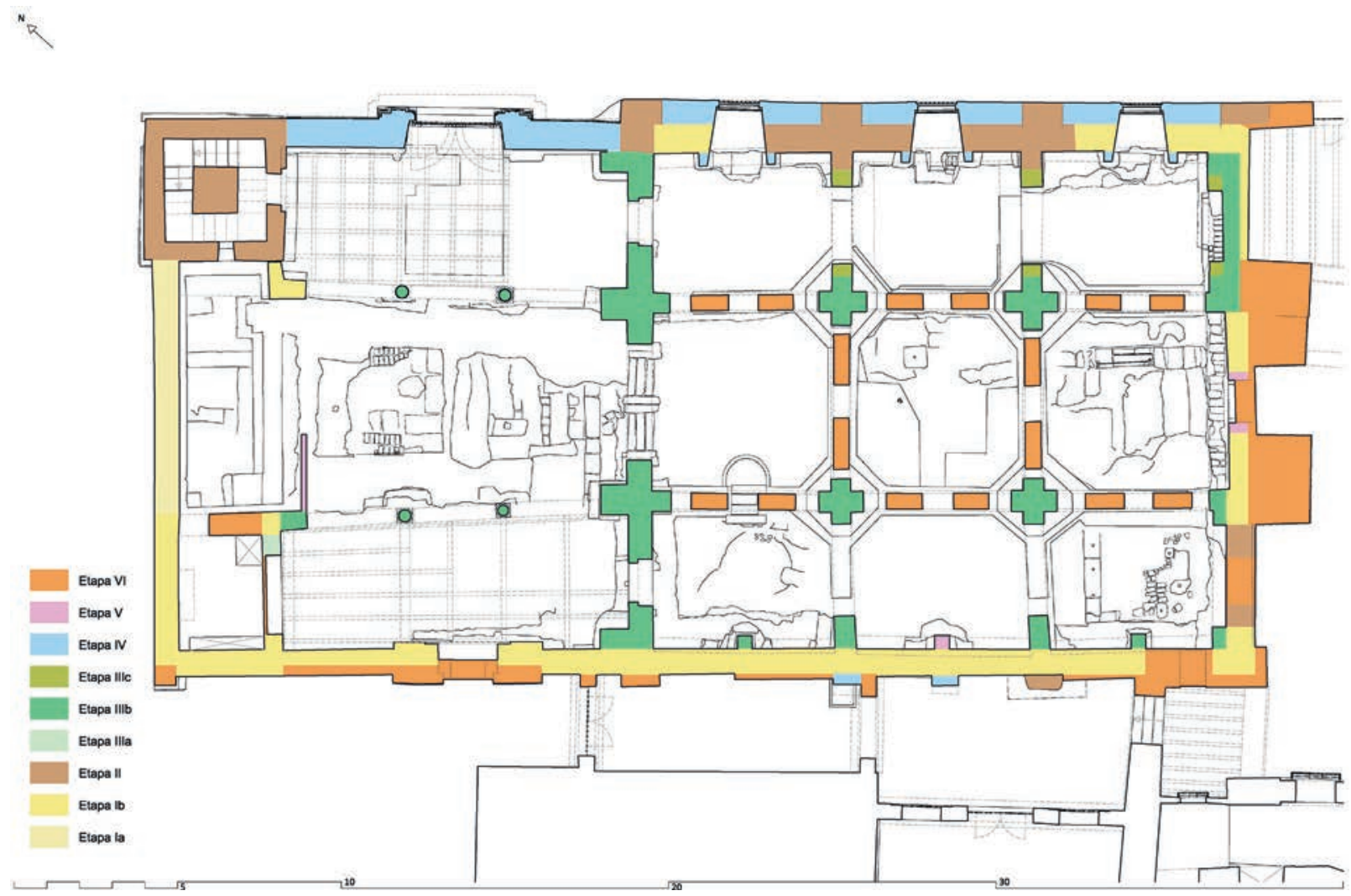

Figura 15. Secuencia evolutiva de la iglesia de Santa Clara (planta baja).

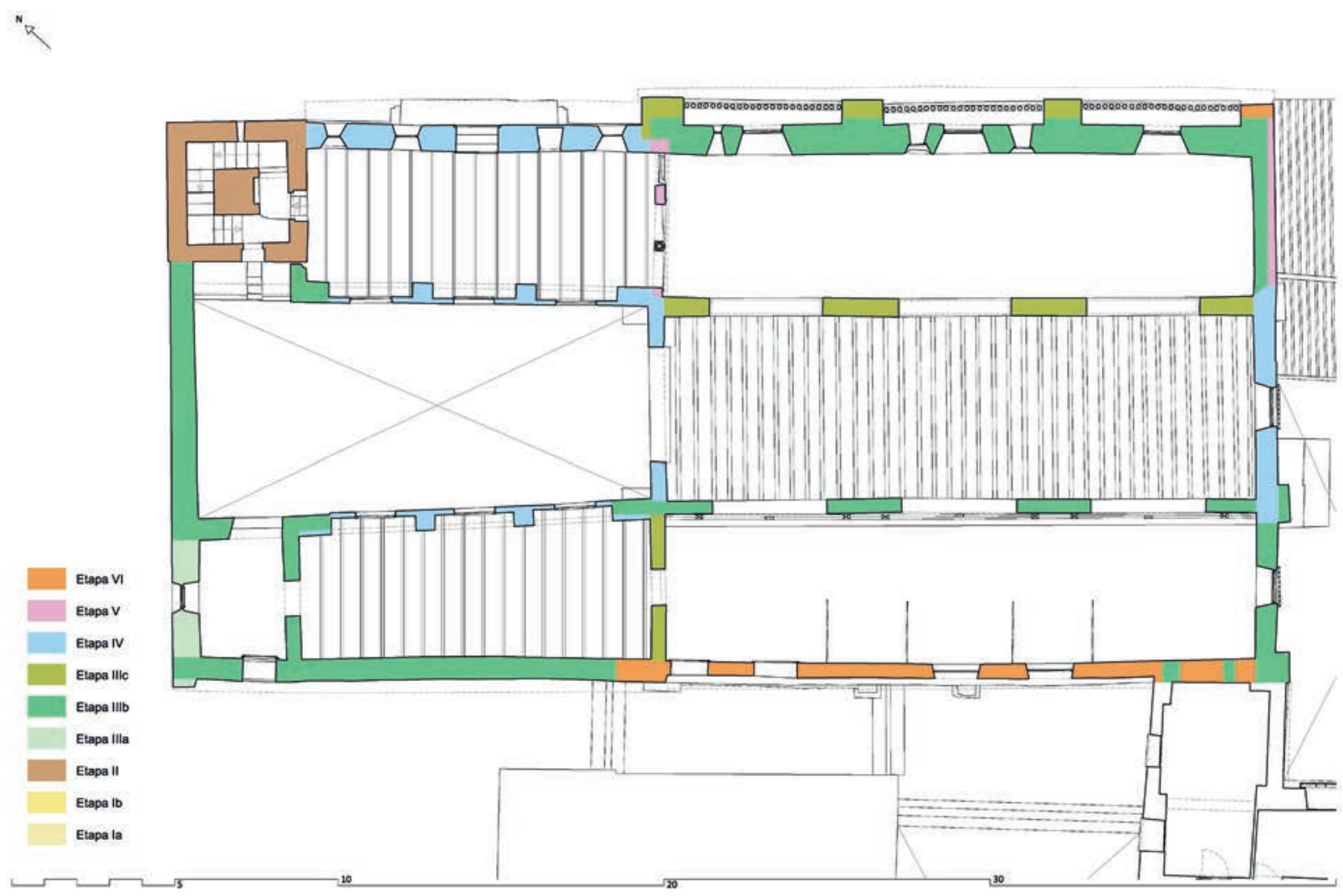

Figura 16. Secuencia evolutiva de la iglesia de Santa Clara (planta alta). 
orientativa que puede ser ampliada con la lectura de la memoria del estudio ${ }^{8}$.

Etapa 0. Las campañas de excavaciones arqueológicas sacaron a la luz los cimientos, pavimentos y umbrales de una edificación que fue interpretada como los restos de una basílica cristiana, del siglo VI (Marfil 1996: 42). Sin embargo, dada la ausencia de mobiliario litúrgico, las diferencias de trazado y los problemas de circulación litúrgica entre las estancias halladas, esta interpretación funcional y su cronología han sido discutidas (Utrero 2009: 144).

Etapa I. La primera etapa constructiva del edificio actual, y que denominamos mezquita, se conforma en planta baja por muros de sillería de aparejo de soga y tizón que llegan en altura en algunos puntos hasta el arranque de la segunda planta (Fig. 17). De este edificio, una mezquita de barrio, aún se conservan elementos delimitadores de su patio, con una puerta originaria en su fachada $\mathrm{SO}$ y la torre alminar. El testero norte de la mezquita (fines del s. X, inicios del XI) fue construido sobre restos de otro muro islámico que perteneció a un edificio previo del que no tenemos más indicios. El alminar, cuyo aparejo de soga y tizón no presenta el almohadillado del cuerpo del edificio de la mezquita, no enjarja con las estructuras que delimitan el patio, lo que deja en duda si perteneció a una edificación anterior o a la mezquita.

Etapas II y III. La iglesia de Reconquista corresponde a un prolongado proceso de adecuación del edificio originario que llega, desde época pleno medieval, a comienzos de la Edad Moderna. Continuas reparaciones sustituyen o se superponen a otros elementos o al espacio arquitectónico definido por la mezquita, sin embargo, sus características son difíciles de encuadrar con precisión cronológicamente. Estas reformas se pueden resumir en cinco actuaciones concretas:

- La adecuación de la mezquita para iglesia, en primer lugar, realizada o iniciada inmediatamente después de la conquista da la ciudad (año 1236) que incluye la restauración de un importante daño que afecta al muro perimetral oriental.

- La intervención en la fachada interior del aula de la iglesia al patio con arcos de medio punto, en el segundo tercio del s. XIII (Fig. 18).

- La reforma de la iglesia para su función monástica, que se debe llevar a cabo en las últimas décadas del siglo

\footnotetext{
${ }^{8}$ Caballero Zoreda, L. 2007: Estudio de Arqueología de la Arquitectura del Convento de Santa Clara de Córdoba. Fundación Caja de Madrid (informe manuscrito): http://multimedia.fundacionmontemadrid.es/patrimonio/santaclara/
}

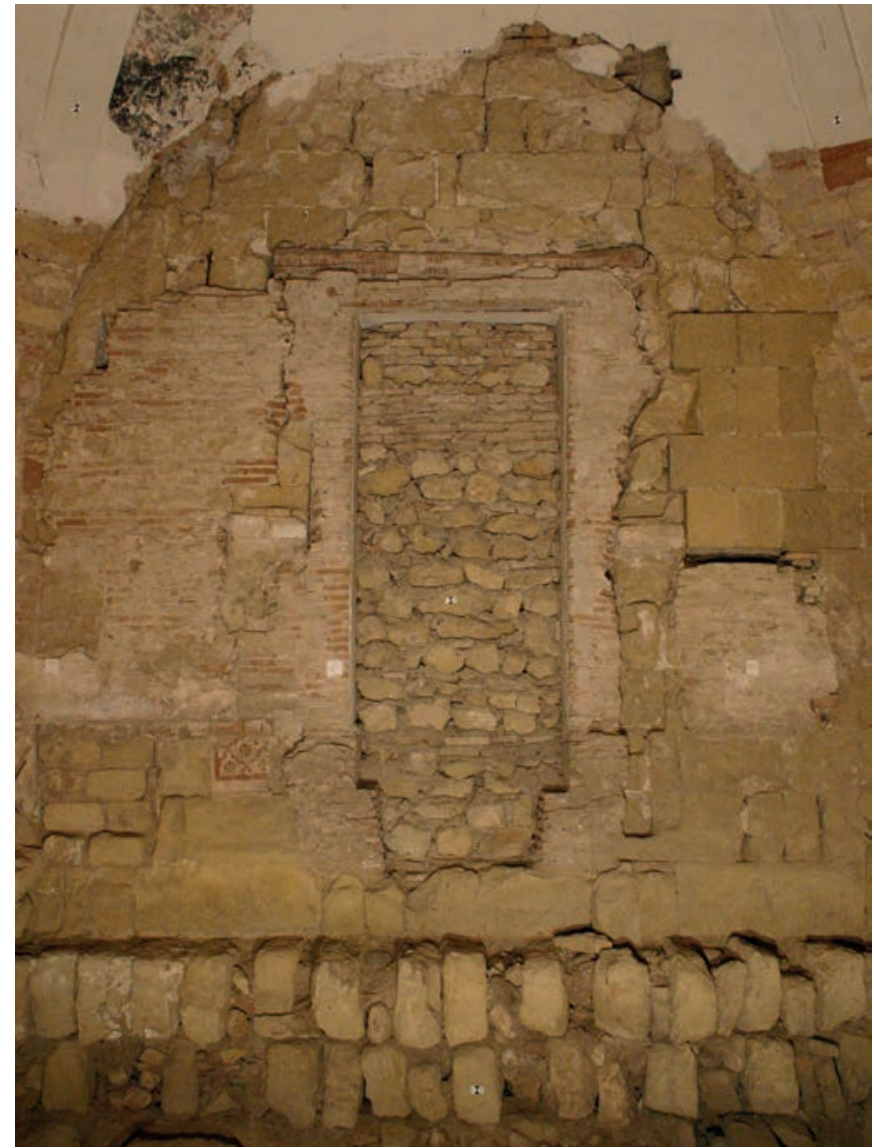

Figura 17. Zona central del testero suroeste del edificio, correspondiente a la qibla de la mezquita.

(alrededor de 1380) supuso su transformación estructural más importante con la inclusión de un sistema de abovedamiento y dos plantas que sustituye al sistema de tejado y artesonado sobre arquerías islámico.

- Quizá a continuación se introduzcan en el cuerpo NO del patio elementos de estilo gótico que no aparecen en la obra principal.

- Y finalmente, se sustituye la arquería oriental de la planta alta de arcos ligeramente apuntados, propios de la segunda mitad del s. XV, lo que podía estar reparando daños estructurales en esta zona (Fig. 19).

Etapa IV. El estadio final en la transformación de la mezquita en una iglesia conventual se lleva a cabo durante el tercer tercio del s. XVIII. La transformación barroca dota a la iglesia de una fachada a la calle haciendo desaparecer el patio que se sustituye hacia donde se reorienta el edificio que ahora dirige el santuario hacia el norte, situando un coro monástico a los pies, donde antes se situaba la iglesia en planta baja. Es probable que en este momento se colocase el artesonado de la planta alta, obra original del siglo XVI, aquí reutilizado. 


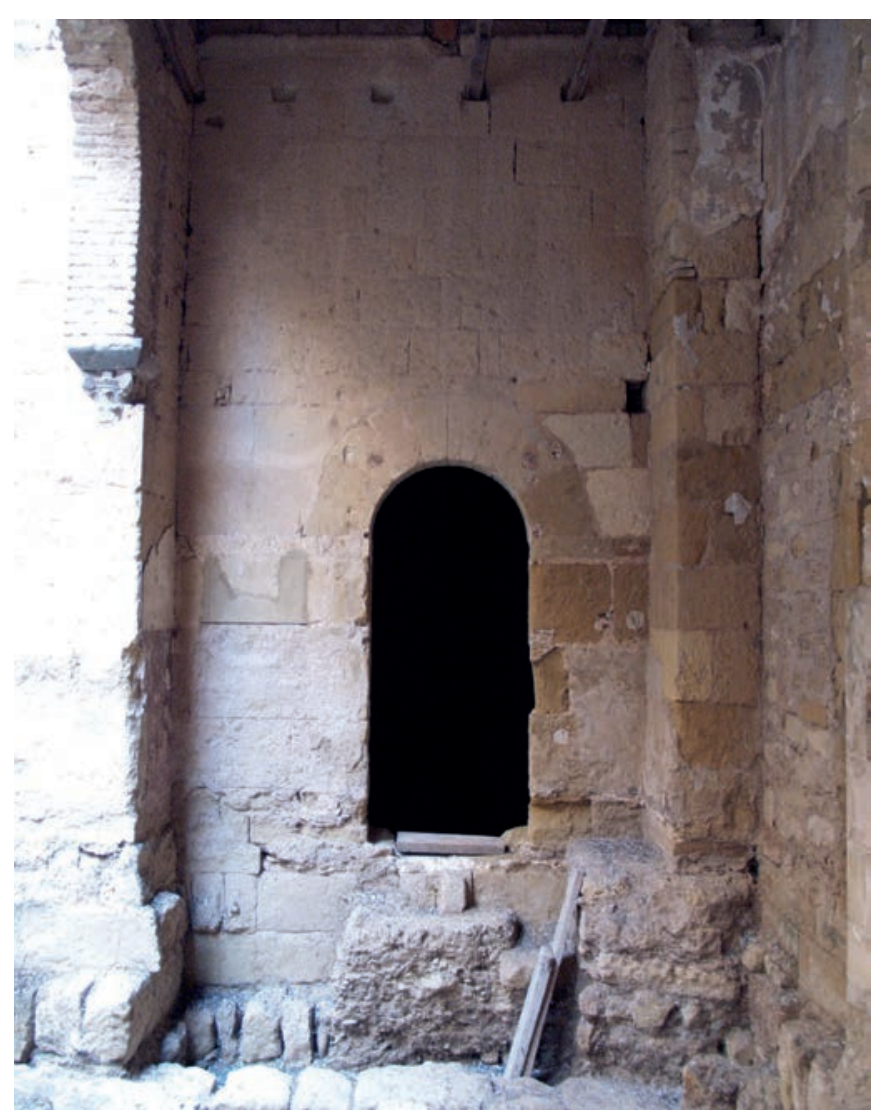

Figura 18. Acceso septentrional de la fachada de la iglesia al patio.

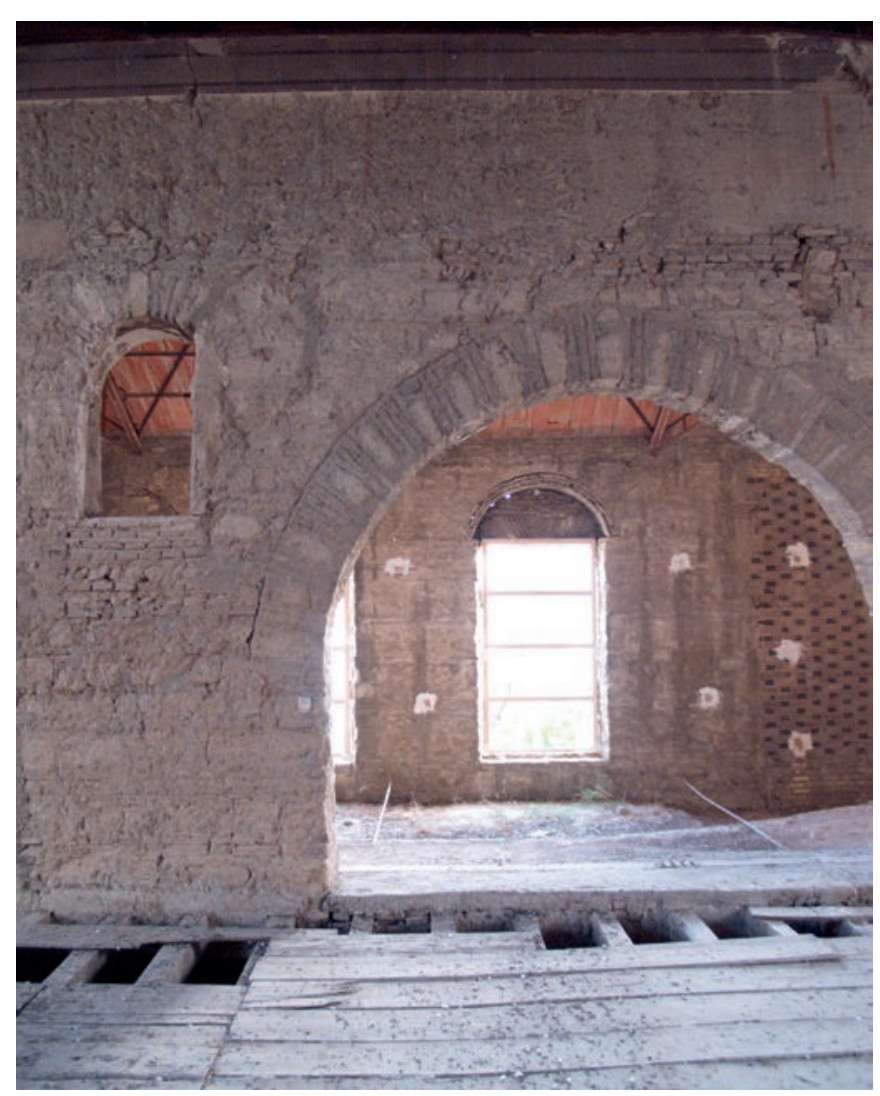

Figura 19. Arquerías de la planta alta.
Etapa $V$. El convento de Santa Clara, una vez suprimido en 1868, fue utilizado, primero como cuartel, para después, vendido a un particular que lo dividió en varias casas, funcionar como mercado y lavadero. Más tarde, paso a las monjas del Servicio Doméstico y en 1962 al Ayuntamiento de Córdoba. Las obras que se realizan durante este periodo se pueden considerar mezcla de utilitarias y de mantenimiento, sin concesiones a la estética. Y el principal efecto corresponde a la recuperación del espacio de patio y de las galerías altas, probablemente al sustituir la iglesia por una pequeña capilla en cualquier otro lugar del complejo, hoy desaparecida.

\section{Historia de las restauraciones de Santa Clara y su impacto en el edificio}

La sexta etapa de transformaciones que vive el convento corresponde a las actuaciones de los arquitectos Víctor Escribano (entre los años 1962-1968), Félix Hernández (entre los años 1971-1973) y Arturo Ramírez Laguna (entre los años 1981-1984 y 1985-2003), este último, apoyado en los resultados de dos campañas de excavación arqueológica (Olmo9; Marfil 1996).

El arquitecto municipal, Víctor Escribano (19641965), detectó la existencia de la mezquita bajo las reformas conventuales y, para sacarla a la luz, destruyó el extremo norte del convento aislando, de este modo, la iglesia. Eliminó los enfoscados decorados de las paredes de la iglesia hasta el nivel del último suelo superpuesto, aplacó los muros primitivos imitando la obra antigua y construyó una entreplanta en el cuerpo norte del patio introduciendo forjados de viguetas metálicas y bóvedas de rasilla.

Financiado por el Ministerio de Educación, Félix Hernández (1975) efectuó el primer análisis de la secuencia evolutiva del monumento, proponiendo ocho grupos de paramentos que secuencia a lo largo de seis etapas. Su intervención, por un lado, intentó recuperar el aspecto de sillería aparejada a soga y tizón de la mezquita originaria y, por otro, consolidar una fábrica que debía ofrecer en esos momentos un aspecto ruinoso y lamentable (Fig. 20). Así que, para compensar el empuje de las bóvedas, ató los muros con abundantes zunchos o tirantes de hormigón o de hierro, normalmente coincidiendo con los tableros de suelo, ocultos al interior por aplacados de piedra.

\footnotetext{
9 Olmo Enciso, L. 1993: "Informe actualizado de la excavación arqueológica en la antigua iglesia de Santa Clara de Córdoba (octubre)", en Ramírez Laguna, A., Estudio Previo. Antigua Iglesia de Santa Clara de Córdoba (manuscrito).
} 


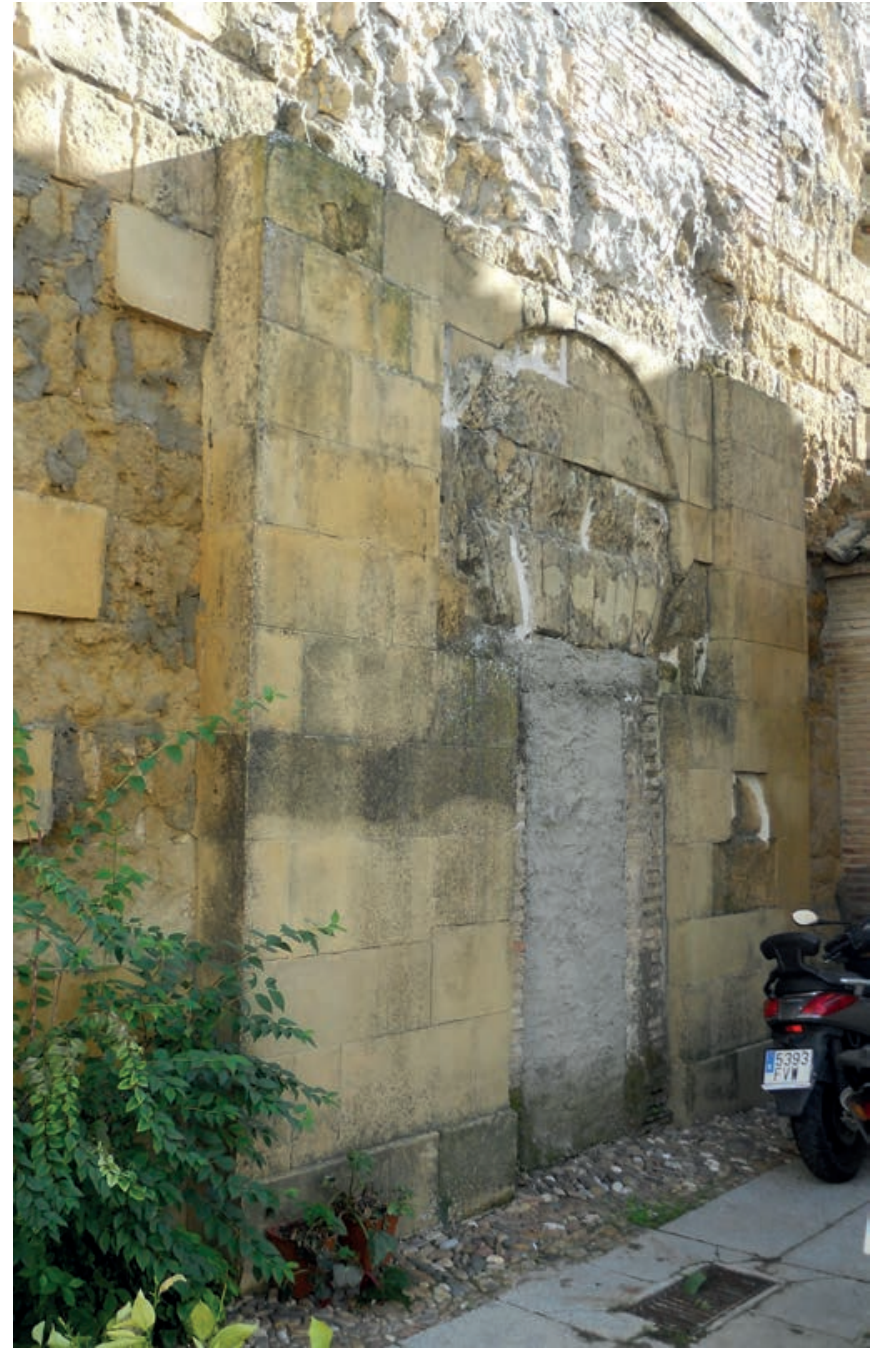

Figura 20. Reparación de muros del acceso original al patio de la mezquita.

De nuevo con el patrocinio del Ayuntamiento de Córdoba, persiguiendo la idea de recuperar el uso como mezquita, Arturo Ramírez Laguna ${ }^{10}$ ofrece la primera reflexión sobre los problemas de estabilidad que muestra el edificio y que atribuye a la dominante oriental de la pendiente, sobre la que se asienta, y a una mala trabazón de algunas estructuras que, acrecentado por el efecto de humedades del subsuelo y goteras, genera sobrecargas y empujes imprevistos. Estas circunstancian le llevan a proponer sustituir el abovedamiento por un forjado de madera, crear un mihrab y desmontar el arco gótico de acceso desde el patio, entre otras cuestiones. Pero, aunque no llega a

\footnotetext{
10 Ramírez Laguna, A. y Fuente Darder, F. de la 1981: Proyecto de consolidación y restauración de la antigua mezquita de Santa Clara en calle Rey Heredia $n^{\circ}$ 22. Córdoba (30 de marzo; manuscrito).

Ramírez Laguna, A. 1993: Estudio Previo. Antigua Iglesia de Santa Clara de Córdoba (manuscrito).
}

ejecutarlas, para reducir empujes elimina estructuras del cuerpo superior y se anclan los extremos del edificio, con el empleo de zunchos de hormigón armado en las cimentaciones y cerchas metálicas para el apoyo de las cubiertas.

Pero, a pesar de esta serie de acercamientos analíticos efectuados a lo largo de los últimos 50 años, los criterios de intervención empleados en Santa Clara no conseguirán conectar la secuencia histórica de su construcción con la dinámica de sus lesiones. Probablemente, porque dominó la búsqueda de una lectura clara de los diferentes ámbitos constructivos de la mezquita, a pesar de que esto supusiera la pérdida de elementos bajomedievales o modernos.

Sin embargo, a mitad de la primera década del siglo XXI, el edificio aún seguía cerrado, ya que las diferentes intervenciones ejecutadas no llegaron a concretar con seguridad las principales lesiones que mostraba el edifico. De hecho, el entresuelo del oratorio se encontraba apeado con muros de ladrillo en los arcos de la planta baja. En este momento, con el apoyo de la Fundación Caja de Madrid, se acometió una nueva serie de análisis, que entre otras actividades incluye una detallada y rigurosa planimetría, coordinada por los arquitectos Pablo Latorre y Leandro Cámara (año 2004), y el estudio anteriormente anunciado, desde el marco metodológico de la Arqueología de la Arquitectura, dirigido por el arqueólogo Luis Caballero (años 2006 y 2007).

\section{Análisis de daños estructurales}

El análisis realizado ha permitido identificar y registrar toda una serie de deformaciones y agrietamientos en los distintos elementos constructivos del edificio (Figs. 21 y 22).

Del mismo modo, se han establecido los bloques en los que queda dividida la estructura (Fig. 12), así como los movimientos que se han identificado (Fig. 23) para proceder después a la interpretación de los daños observados, cuya síntesis ofrecemos a continuación.

Se detectan movimientos de inclinación (generalmente hacia el exterior del edificio) y descenso de los muros de toda la obra que comienzan en los primeros momentos de construcción de la mezquita islámica y siguen activos hasta hoy día, pues afectan a todas las fases de todas las épocas, incluidas las más recientes. Sin embargo, estos movimientos se desarrollan muy 


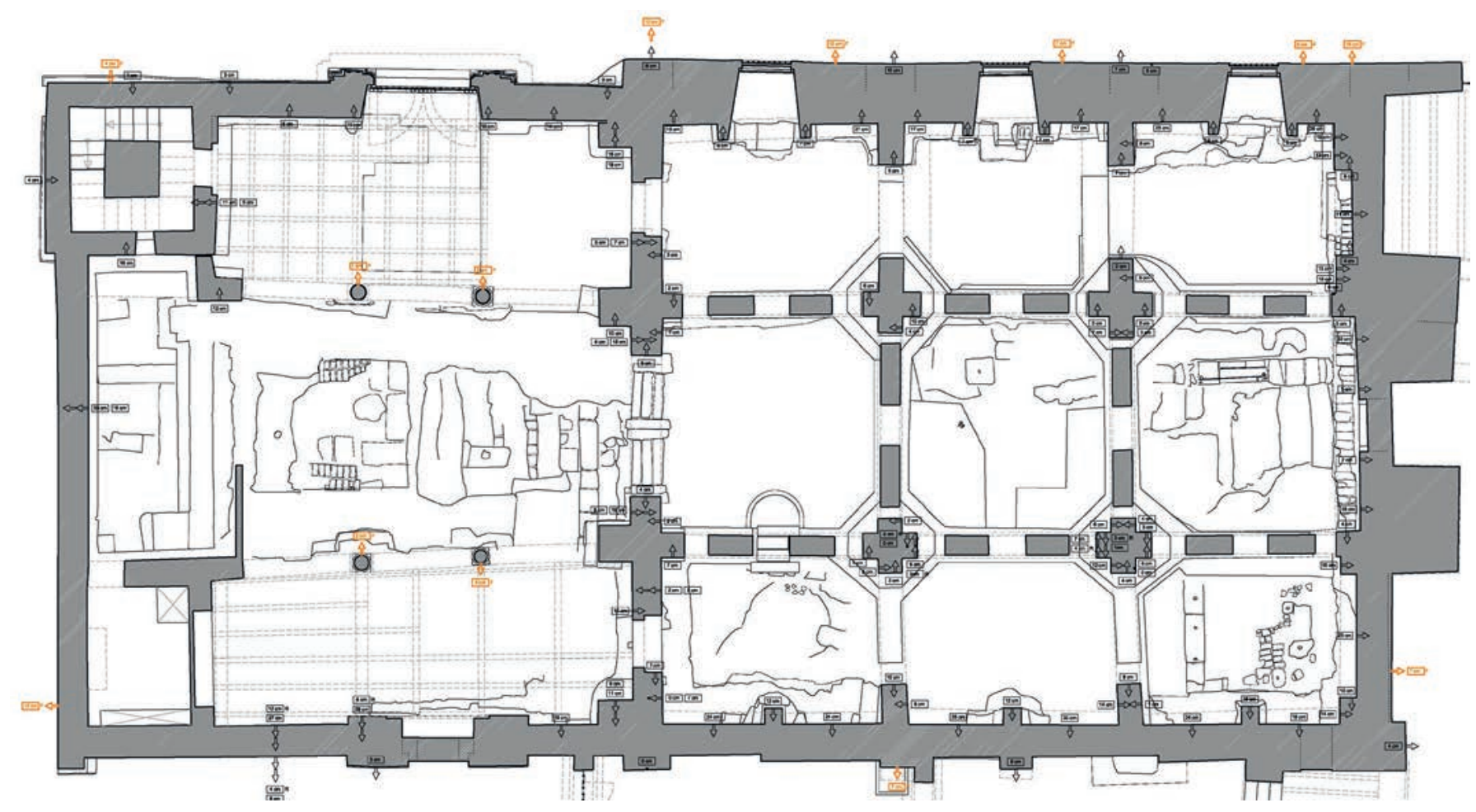

Figura 21. Registro de lesiones en la planta baja.

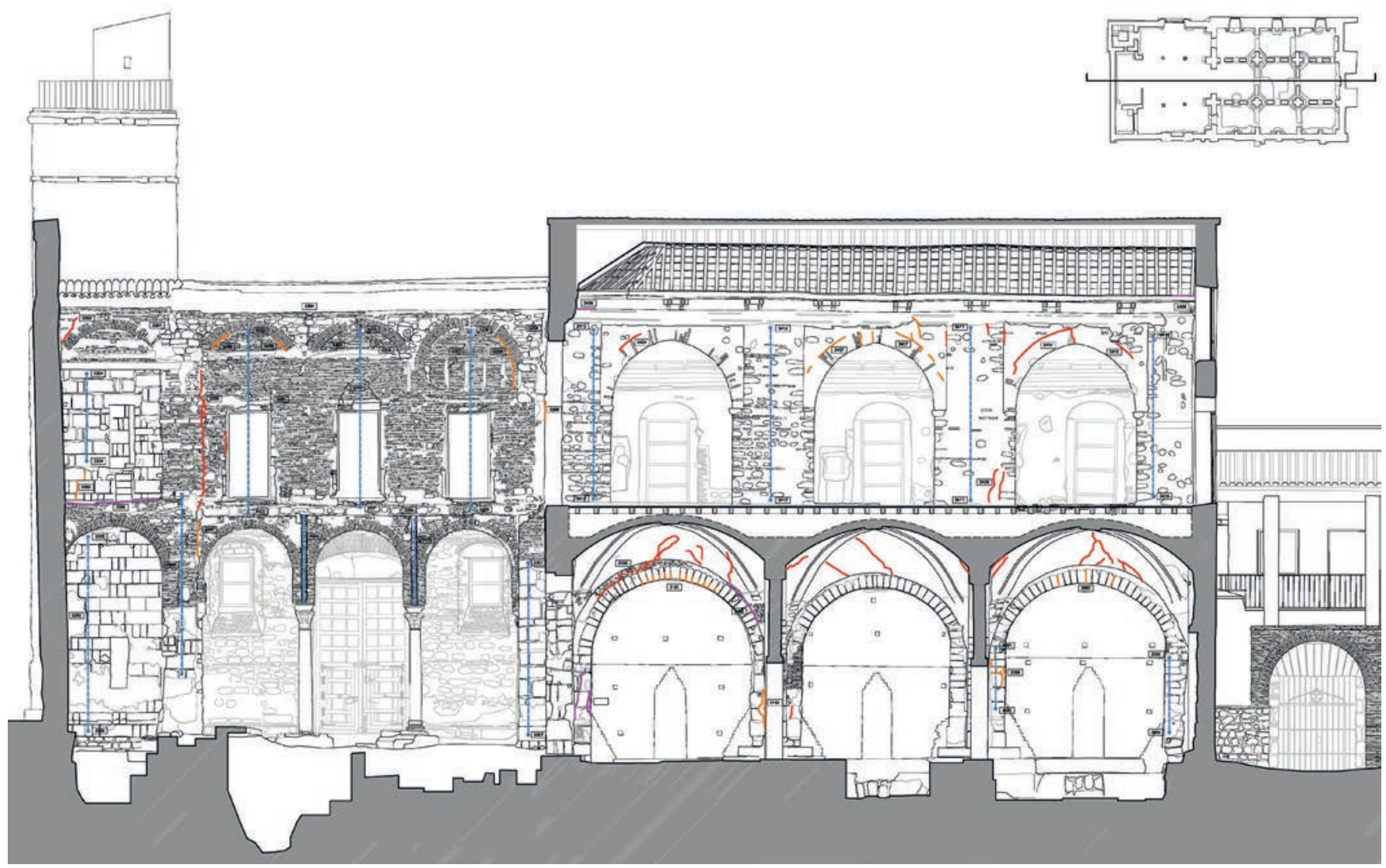

Figura 22. Registro de lesiones en una sección longitudinal. 


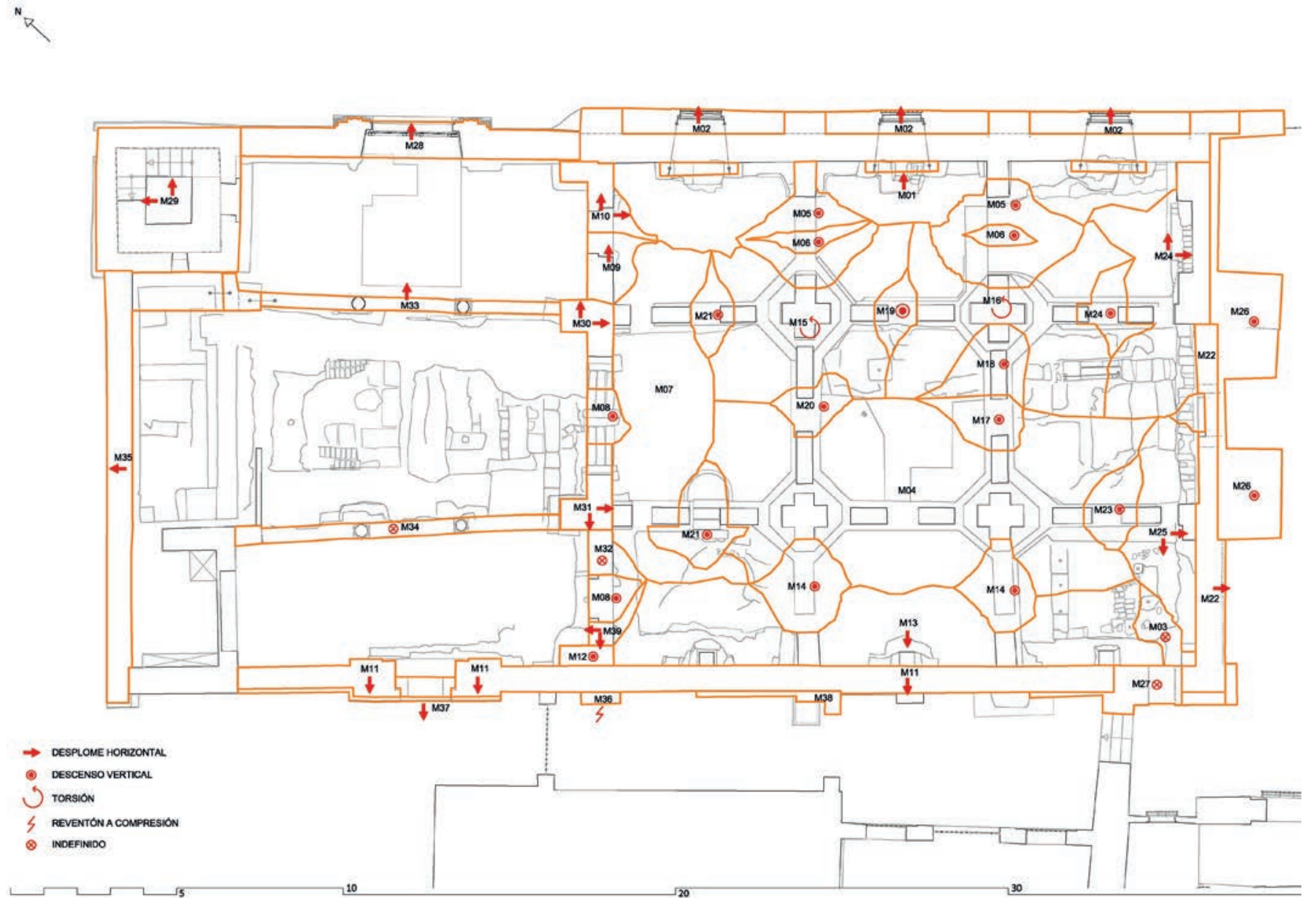

Figura 23. Movimientos identificados en la planta baja del edificio.

lentamente, lo que viene indicado por el mayor desplome de los muros más antiguos, que aparentan acumular el de todos los demás. Por ello, las obras más recientes habrían tenido movimientos de menor amplitud, y en algunos casos despreciables.

El estudio geotécnico realizado nos indica la existencia de un fuerte nivel de rellenos antrópicos, de entre tres metros de espesor (en el lado este) y hasta ocho metros (en el lado sur). Esto nos confirma en nuestra apreciación de que es la deformabilidad del terreno la que explica los asientos y giros de la estructura. Tras el estudio de cargas realizado, podemos concluir que el terreno tiene una resistencia residual prácticamente igual a la de las cargas del propio edificio (pues lo soporta), mientras que su evolución (consolidación) a largo plazo es lenta pero imparable, motivo por el cual en los lados oeste y sur del edificio, donde el estrato es más espeso, los asientos y giros no parecen haberse detenido todavía, mientras que sí parecen prácticamente detenidos en el lado este.
De este modo, la estructura en su conjunto sufre dos procesos de daño muy intenso. En primer lugar, el progresivo giro de cada muro respecto de sus muros paralelos hace que todos los paños se agrieten y los arcos y bóvedas sufran descensos en sus zonas de clave. En segundo lugar, la combinación de movimientos en dos direcciones distintas, o lo que es lo mismo, en diagonal a las direcciones principales del templo, provoca unos efectos de torsión y cizalladura muy intensos en los elementos más esbeltos. Por ello, los elementos más dañados son los cuatro pilares en cruz del centro del aula, donde se aprecian agrietamientos muy importantes y fracturas de sus sillares que sólo se explican por esfuerzos de corte muy fuertes (Fig. 24), y la torre, formada por dos elementos muy distintos (el núcleo macizo y su envoltorio exterior) conectados por unos peldaños muy frágiles, los cuales sufren fracturas generalizadas debidas al giro desacompasado de aquellos. 


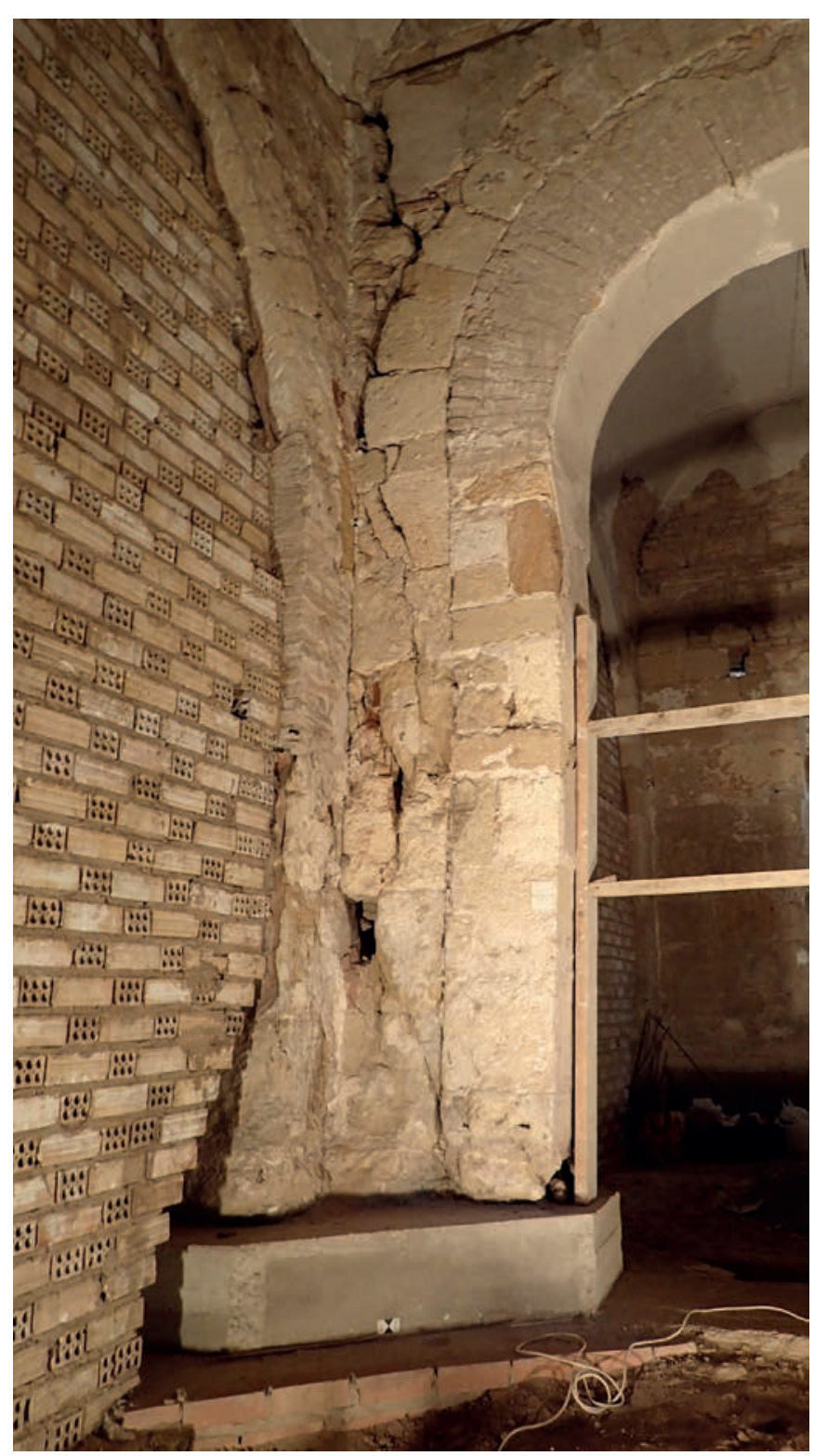

Figura 24. Pilar cruciforme del interior la iglesia con fuertes deformaciones y agrietamientos.

Sin embargo, la estabilidad general de las estructuras de arcos y bóvedas no parece comprometida por esos movimientos, pues aunque se acusen grietas y descensos en algunas de sus claves, los arcos no han dejado de trabajar como deben (lo cual se comprueba a raíz del cálculo realizado, de modo que es posible mantener sus líneas de presiones dentro de las secciones constructivas).

Por el contrario, sí son muy apreciables los daños en los materiales constructivos con origen no estructural (desprendimiento de revestimiento y erosiones superficiales intensas). Es especialmente grave la erosión de la base de la torre y de los cuatro pilares cruciformes del aula, que aun no teniendo origen estructural (probablemente provocada por el ascenso capilar y la evaporación superficial del agua del terreno), sí es potencialmente peligrosa para la estabilidad del conjunto, pues hace que la pérdida de sección resistente de éstos pueda llevar a un colapso de la obra (Fig. 25).

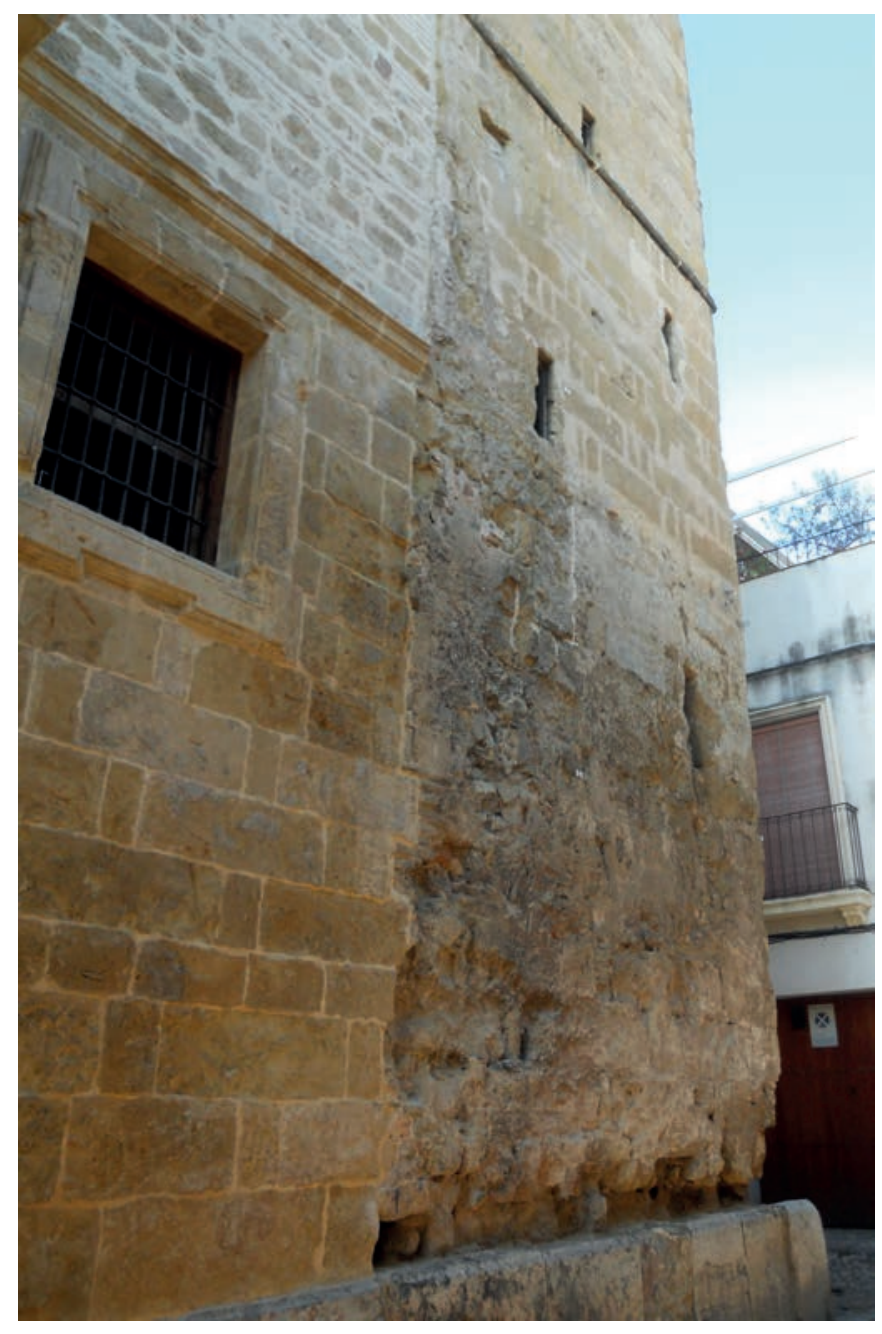

Figura 25. Erosión de los sillares en la parte baja de la torre.

Por ello, hay que destacar que estos elementos (pilares y torre), sufren la concurrencia de dos patologías muy importantes. Por un lado, los agrietamientos y fractura de sillares debidos a los desplazamientos estructurales y, por otro, la pérdida de sección resistente de los sillares en sus arranques debida a la fuerte erosión.

Además, cabe añadir que tanto los refuerzos de los cimientos con hormigón armado como los contrafuertes adosados en distintas partes de la estructura, especialmente los realizados en el muro sureste para luchar contra su muy evidente y progresivo desplome, son todo menos eficaces frente al problema de suelo que origina los daños, pues cualquier aumento de las cargas en este 
terreno con relleno antrópico provoca una reactivación o aceleración de los procesos de asiento, al tratarse de terreno muy compresible e inestable, y el resultado es un empeoramiento de la situación de partida. Además, este terreno altamente compresible es también muy sensible a la diferencia de tensiones de trabajo en cada parte de la cimentación. La concentración de cargas puntuales provoca nuevamente asientos mayores que los que producen cargas más uniformemente repartidas.

Los recientes apeos de los arcos mediante muros de ladrillo no son ni eran necesarios en ningún momento, dado que esos arcos se encuentran en muy buen estado estructural, sin pérdidas de curvatura notables (Fig. 26). No obstante, son un elemento más de sobrecarga en el terreno, a sumar al problema general y principal de la iglesia. Caso distinto es la colocación de los arcos de ladrillo de apeo hechos en época barroca bajo los de cantería de la nave sur de la iglesia, donde sí han contribuido a la estabilidad del arco al reconducir las cargas superiores de manera más centrada en los cimientos, evitando su salida del área de apoyo de las zapatas.

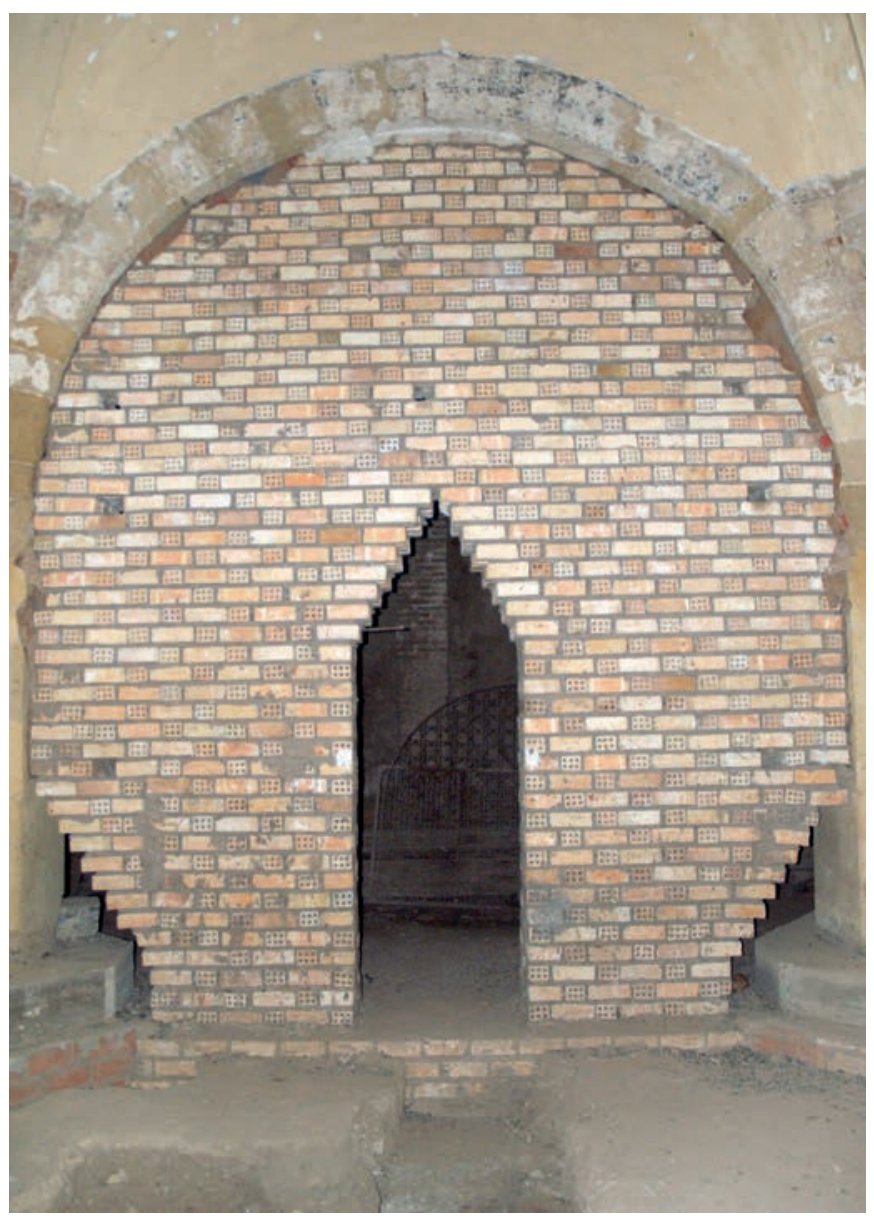

Figura 26. Apeo de arco con muro de ladrillo.

\section{Evolución histórica de la estructura}

Siguiendo la metodología expuesta en el apartado anterior, tras el análisis de las lesiones y las causas que los producen, se han agrupado posteriormente los movimientos individuales en grandes desplazamientos, sintetizando de este modo los procesos patológicos que afectan al edificio. Desde el punto de vista metodológico, hay que entender que los movimientos dentro de la estructura se producen "relativamente", es decir, de unas partes en relación con otras. La carencia de elementos de referencia absolutos que nos permitan referirnos a una hipotética condición original de estabilidad total nos conduce a tener que proceder por comparación de unos elementos con otros. Además, cada uno de estos grandes desplazamientos se ha introducido en el diagrama estratigráfico, integrándose así el análisis patológico con la lectura arqueológica del edificio (Fig. 13). Este ejercicio muestra cómo los grandes movimientos, frente a la posición fija que ocupan las UE constructivas en el diagrama estratigráfico, cuando corresponden a procesos activos, pueden ocupar una posición en varios puntos de la secuencia.

De este modo, en la zona correspondiente al aula de la iglesia, se han distinguido los siguientes grandes desplazamientos (Fig. 27 y 28):

$G D 0$. corresponde a la zona del edificio que parece no haberse movido significativamente en ninguna dirección, que vendría a ser la parte central y los dos pilares situados en el muro-arcada derecho (oeste) de la nave central. Por ello hemos establecido esta parte de la iglesia como la de nulo movimiento, refiriendo los demás giros o asientos a la estabilidad de esta parte. GD1: es el giro del muro exterior de la iglesia y el patio, fachada noreste, hacia el exterior. Es el desplazamiento más acusado de todos los detectados, lo que es lógico al tratarse del muro que conserva las partes más antiguas de la construcción. Históricamente este desplazamiento ha ido afectando a todos los elementos constructivos añadidos o reparados en el muro, desde las pilastras y abovedamientos bajomedievales hasta los de fecha barroca. Entendemos que su origen se encuentra en un asiento diferencial del cimiento en el terreno combinado con un proceso de deformación progresiva del propio suelo. Afecta a todas las fases históricas excepto a las últimas actividades del siglo XX, por lo que entendemos que se encuentra detenido desde este momento. GD2: es el giro del muro-arcada interior noreste, entre la nave central y la izquierda, en la misma dirección que el 


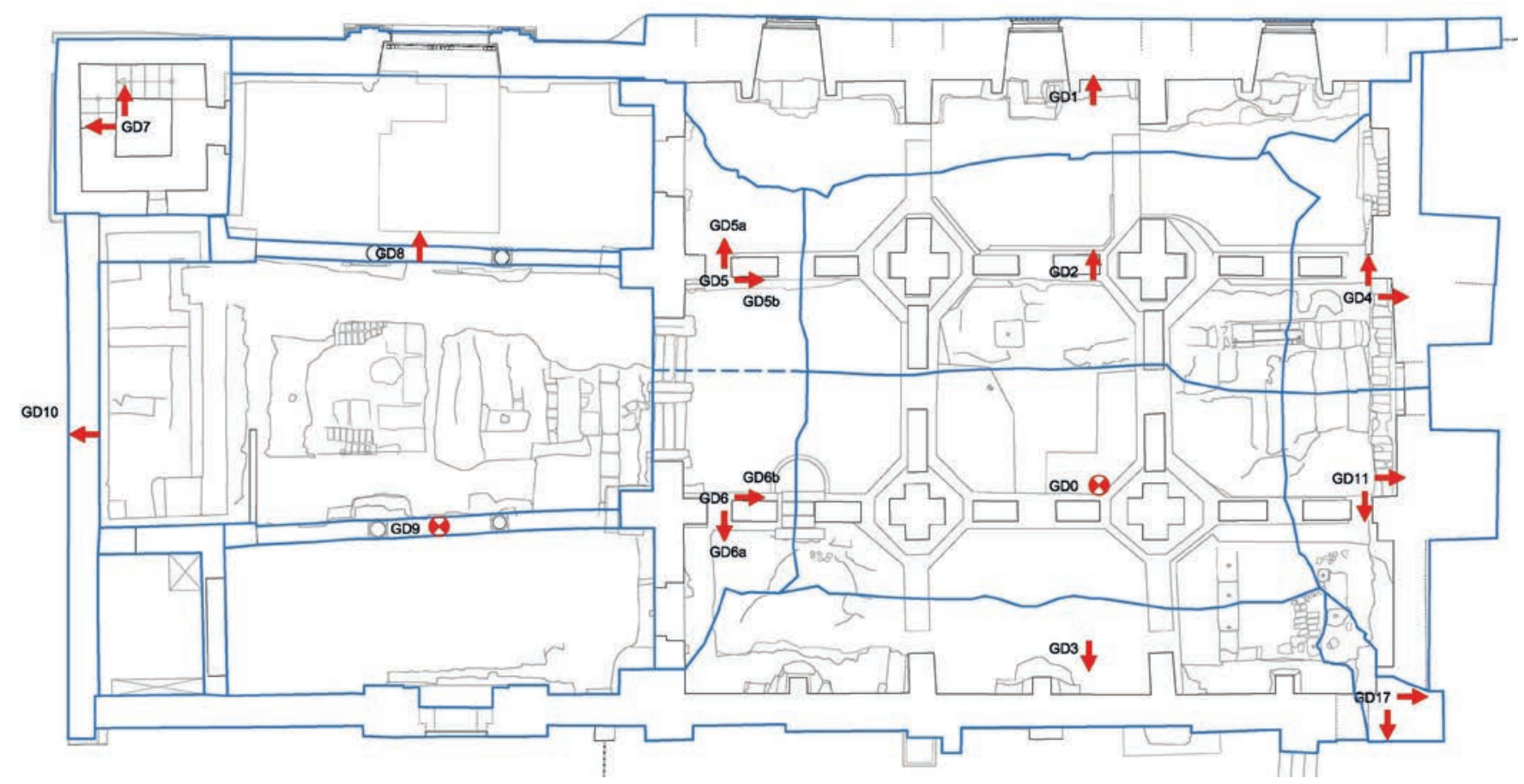

Figura 27. Grandes desplazamientos en la planta baja.

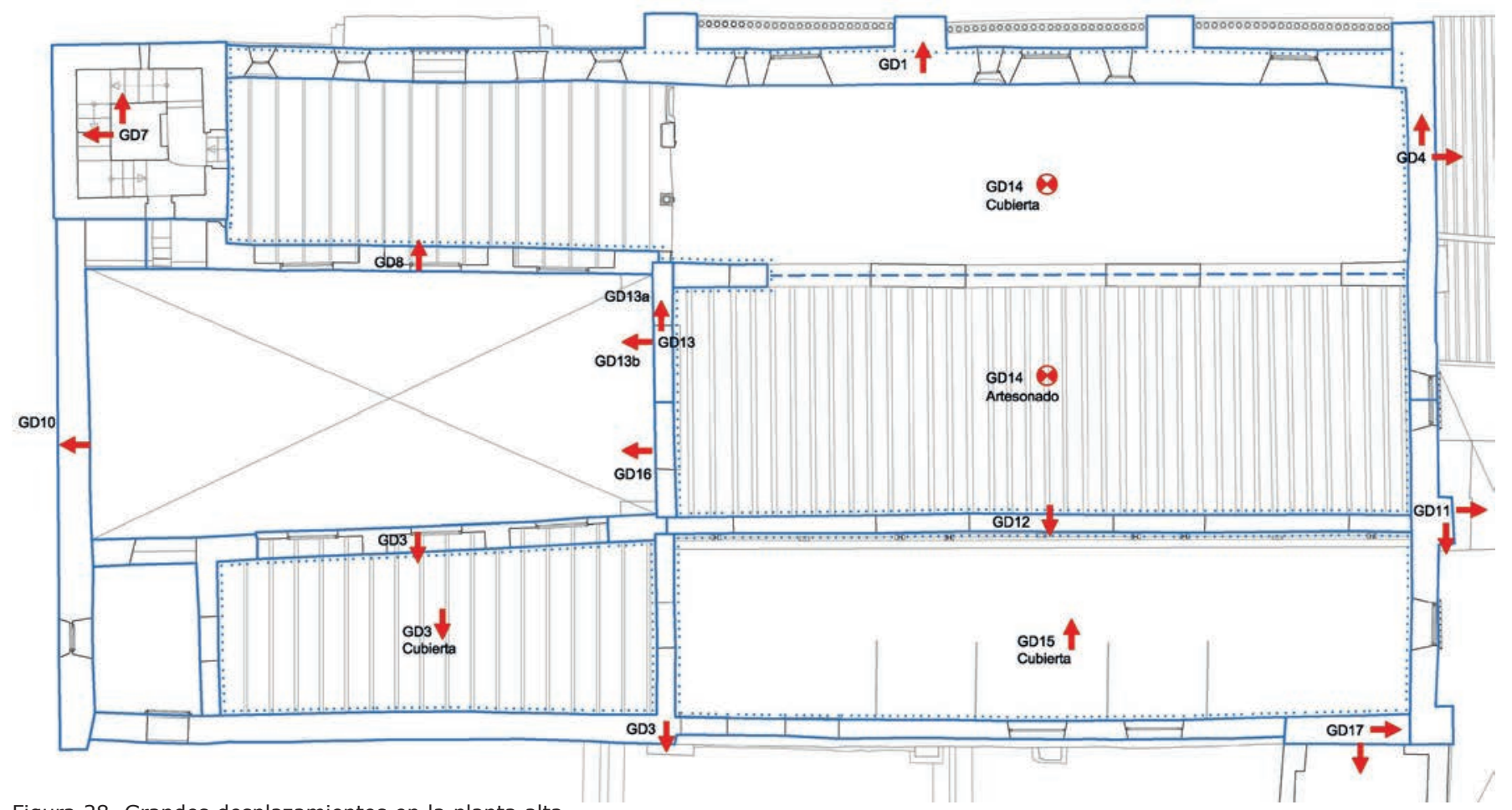

Figura 28. Grandes desplazamientos en la planta alta.

movimiento anterior pero de menor desarrollo. También parece obedecer al mismo fenómeno de asiento y giro del cimiento, con sus componentes inclinadas al exterior debido a los empujes de las bóvedas. Este movimiento afecta a todas las fases hasta el siglo XIX, pero no se puede evaluar si afectaría a las del siglo $\mathrm{XX}$, por no encontrarse ninguna de estas en su zona de afección. No podemos concluir por tanto que se encuentre detenido. GD3: en el lado contrario de la iglesia, fachada suroeste, se encuentra un movimiento de signo contrario al anterior, es decir, hacia su exterior. Este movimiento también ha arrastrado a las fábricas del piso superior 
y parece tener un origen simétrico del de la fachada noreste, es decir, un asiento y giro en el terreno debido a su deformabilidad y a la inclinación de la resultante de las cargas por acción de los empujes de las bóvedas $\mathrm{y}$ arcos. Es aparentemente un movimiento de menor magnitud que el del lado contrario, lo que en una lectura sincrónica nos llevaría a afirmar que el problema es menor en este lado del edificio. Sin embargo, una lectura temporal de las fases constructivas presentes en el muro revela que todo el piso superior es de muy reciente construcción, lo que induce a pensar que el problema de asientos es más grave ahora en este lado suroeste que en el opuesto, pues no se encontraría detenido todavía y estaría provocando que el muro siga en un proceso de inestabilidad progresiva no detenida. GD4 y GD11: son dos movimientos que afectan al muro sureste con una componente igual y otra componente simétrica a un lado y otro del eje principal del edificio. El muro se inclina en conjunto hacia el exterior, lo que habría provocado graves desplomes que se intentaron contener con los grandes machones de refuerzo exterior. Pero además, se encuentra la componente simétrica del movimiento que produce la fractura vertical del muro hastial prácticamente en su centro. Nuevamente, estos movimientos se manifiestan en la planta alta con una intensidad mucho menor. En definitiva, y dado que esta parte de la obra es también de época bajomedieval, podemos casi establecer que el movimiento de este muro se ha detenido o ralentizado muchísimo desde hace ya varios siglos y que, por tanto, el fenómeno que lo produjo se ha desactivado prácticamente.

GD5 y GD6: como los anteriores, se trata de dos giros con una componente igual y otra simétrica afectando a las dos mitades del muro de cierre noroeste del aula de la iglesia. En la planta alta, los movimientos GD13 y GD16 son parcialmente divergentes, pero dado que tienen mucha menor amplitud e intensidad, podría significar que las causas que los provocan se hallan ya detenidas desde el bajomedievo.

GD12: se trata del movimiento hacia el oeste de la arquería oeste de la planta superior. Puesto que sólo afecta a este elemento, de etapa bajomedieval, entendemos que aparentemente se encontraría detenido. GD13: es el movimiento del muro noroeste en su mitad este. GD13a acompaña al GD8, mientras el GD13b acompaña al GD16, afectando ambos a etapas hasta el barroco, y no viéndose cancelados posteriormente por no existir obras posteriores en las que se pueda encontrar el movimiento.
GD14: es el "no movimiento" o estabilización relativa de la cubierta artesonada, del faldón de la nave este de la iglesia y de la arcada superior en que ambos descansan. Al igual que con el movimiento GD0, los movimientos de todos los otros cuerpos y bloques alrededor de GD14 indican que este es el más estable. En definitiva, parece que este tramo inmóvil nos da la clave de que los movimientos en la parte central y este del edificio se detuvieron hacia finales de la edad media, cuando se construye la arcada este de la planta alta y se recoloca el artesonado. En todo caso, afecta a elementos muy modernos (cubierta este) y parece indicar que esta parte por fin se ha estabilizado recientemente.

GD15: se trata de un movimiento sustancialmente diferente de todos los anteriores, pues afecta a un bloque sin contacto con el terreno. Se trata por tanto de un movimiento relativo interior a la propia estructura que afecta a la cubierta de la nave suroeste, que se habría hundido parcialmente hacia el interior de la iglesia, provocando la deformación de sus cerchas. No tiene por lo tanto origen en el comportamiento del terreno ni repercusión grave en el equilibrio general de la fábrica.

GD17: se trata del movimiento de la esquina sur del edificio hacia el exterior. Afecta hasta la etapa barroca, pero nuevamente sin etapas posteriores que lo cancelen.

Por otro lado, en la zona del patio y la torre, se han distinguido los siguientes grandes desplazamientos:

GD7: es el giro de la torre hacia el noreste, con dos magnitudes diferentes para el cerramiento perimetral y el núcleo central. El giro parece tener el mismo origen en el asiento diferencial del terreno, y afecta a las dos fases de la torre (la musulmana inferior y la plenomedieval románica del recrecido). Aun siendo menor el giro de la parte alta, no podemos afirmar que el fenómeno esté detenido, pues no encontramos elementos modernos de cierta entidad que nos permitan comprobar su estabilización final.

GD8: se trata de la pequeña inclinación que ha asumido el muro y la arcada del patio hacia el noreste. Afecta tanto a la planta baja (en mayor medida) como a la superior (en menor medida), por lo que parece tener también un origen en el cimiento y podría también estar prácticamente detenido.

GD9: en la arcada opuesta es, como el GD0, un "movimiento nulo", detectado en unas inclinaciones tan pequeñas que pueden ser despreciables. Esto nos permite decir que, en continuidad con el tramo afectado 
por GD0, encontramos en este muro-arcada la parte inmóvil del conjunto de la estructura.

GD10: se trata del giro hacia el noroeste del muro hastial de cierre del patio configurado en dos etapas constructivas que se encuentran, ambas, inclinadas notablemente hacia el exterior. Nuevamente el giro parece arrancar desde el cimiento y deberse por tanto a asientos diferenciales en el terreno. Parece afectar a todas las etapas, incluido el último recrecido de finales del siglo XX. Aparentemente sería un movimiento activo, no estabilizado ni cancelado por ninguna etapa reciente.

En definitiva, parece deducirse que los movimientos más importantes, los que han afectado a las partes más significativas del edificio, parecen estar casi detenidos. Los indicios en la planta baja no son concluyentes por sí mismos porque no afectan a todas las etapas históricas, pero los de la planta alta, que sí lo hacen, parecen indicar esa mayor estabilidad, puesto que los movimientos no parecen afectar a las etapas más recientes. Y si la planta alta se ha estabilizado, podemos deducir casi con entera certeza que la planta baja no se habrá movido tampoco en el mismo periodo, por lo que podríamos considerar que también se ha estabilizado. Frente a ese panorama, las fachadas suroeste y noroeste, así como la torre, sí presentan signos de que sus movimientos evolucionan todavía, sin etapas que los detengan. De ellos el más grave aparentemente es el del muro suroeste, que ha dañado seriamente incluso alguno de los refuerzos e intervenciones más modernos.

\section{Cálculo estructural}

Con posterioridad al análisis diacrónico que nos muestra la evolución de la estructura a lo largo del tiempo, se ha procedido al análisis sincrónico del estado actual mediante el cálculo estructural de los muros interiores del edificio (los que contienen arcos), pues son estos los que transmiten esfuerzos horizontales al terreno, además de concentrar las cargas en puntos singulares de la estructura (pilares y pilastras). La elaboración de sus diagramas de cargas y líneas de presiones vienen a mostrar el modo en que se transmiten y descienden las cargas gravitatorias de los distintos elementos constructivos para llegar hasta el terreno de asiento, especialmente en relación con los arcos y su funcionamiento estructural.

Sin entrar a detallar esta parte del análisis (ya que excede el objetivo metodológico de este artículo), sí cabe mencionar que en cada uno de los muros analizados se ha realizado un doble cálculo que se corresponde con dos hipótesis extremas del comportamiento de los arcos (Fig. 29). La primera hipótesis es la que considera un empuje mínimo en el arco que sea capaz de conducir las cargas verticales dentro de la sección constructiva. Desde el punto de vista físico esto responde a la situación real o más probable de trabajo de los arcos, ya que responde al principio de mínima energía general en la naturaleza.

La segunda hipótesis considera el máximo empuje que los arcos serían capaces de soportar, representando la situación anterior al colapso que se pudiera producir por la introducción de una acción exterior. Dicha acción podría ser horizontal, en el caso de un terremoto "máximo" que podría resistir la fábrica aumentando el empuje de los $\operatorname{arcos}^{11}$, aunque también podría implicar una carga vertical concentrada en algún arco para cuya reconducción hacia el apoyo fuera necesario que el empuje se hiciera muy grande y comprometiera el equilibrio de los arcos adyacentes.

Ambas son por tanto las situaciones límite de la estructura considerada. Cualquier otro empuje de rango intermedio sería resistido por la fábrica, mientras que empujes de magnitud menor o mayor provocarían un desequilibrio del sistema.

Los resultados del cálculo vienen a confirmar lo que la iglesia nos dice por sí misma: que ha sufrido fuertes asientos al sobrepasar los valores estimados de la resistencia del terreno, mientras que no presenta ningún problema en la fábrica propiamente dicha, más que los derivados de esos asientos diferenciales que acarrean giros y grietas en la fábrica. Además, se han detectado algunos puntos críticos de la estructura, donde la línea de presiones se acerca peligrosamente al límite de la sección construida, lo que puede suponer un riesgo para la estabilidad de la estructura. Este es el caso de los pilares cruciformes del aula, donde tanto el descentramiento de la carga como la degradación de su base hacen que éstos sean los elementos más débiles y precarios en cuanto al equilibrio de la estructura, requiriendo sin duda una intervención para mejorar su situación.

\section{Diagnóstico integrado del edificio}

La combinación de los dos análisis (uno de tipo diacrónicoevolutivo y otro de tipo sincrónico) y su contextualización

\footnotetext{
11 En relación con la patología de estructuras de fábrica asociada a movimientos sísmicos, puede consultarse Ruiz Jaramillo, J. 2016: Comportamiento Sísmico de Edificios Históricos. Las Iglesias Mudéjares de Sevilla. Tesis Doctoral. Universidad de Sevilla, Sevilla, capítulo 2.5.10.
} 

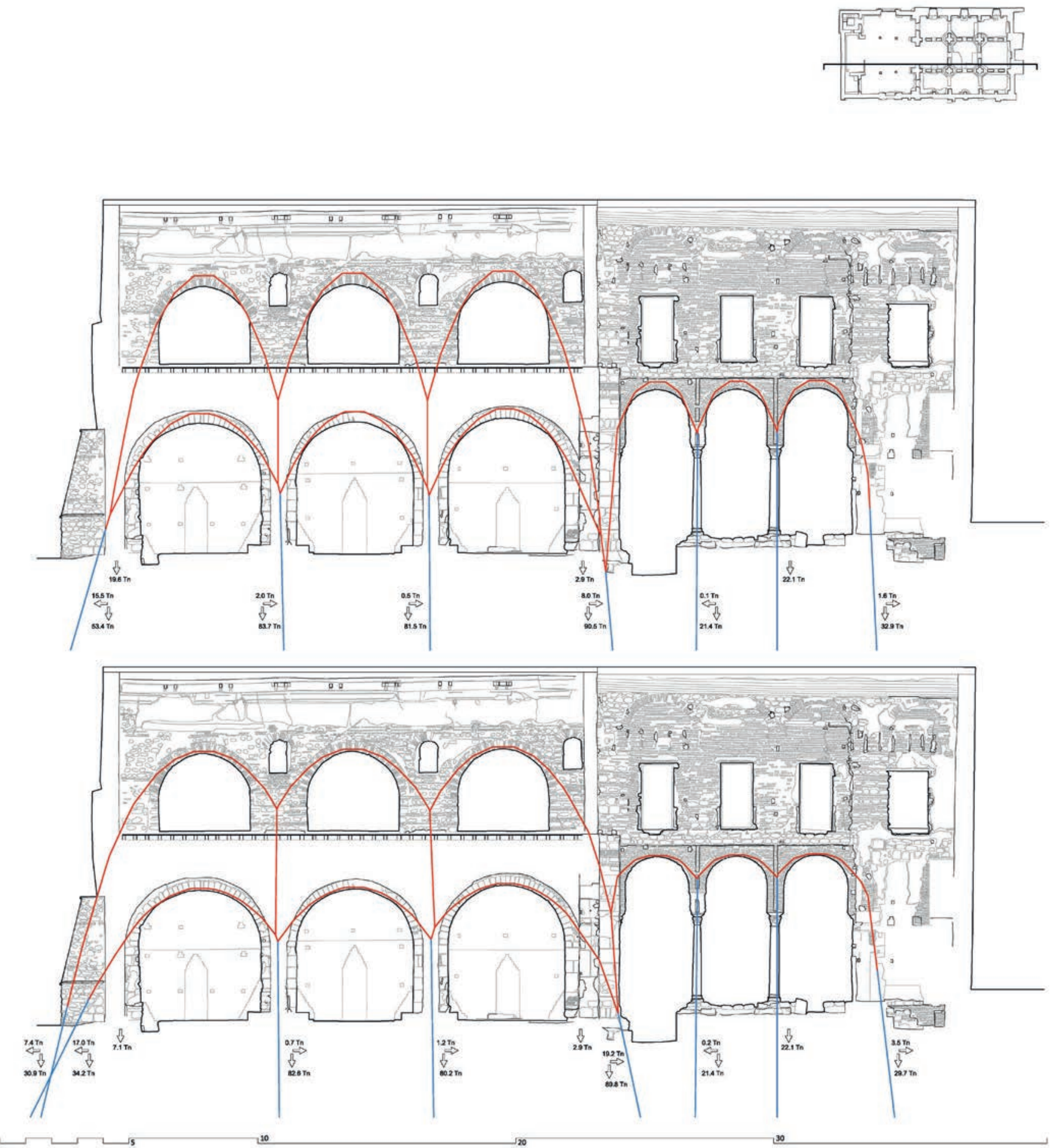

Figura 29. Cálculo de empujes según las dos hipótesis extremas. 
en el estudio de la secuencia histórico-constructiva ha permitido obtener una visión global y rigurosa del comportamiento de la estructura y de la gravedad de sus problemas patológicos (Fig. 30). De estos análisis se desprenden unas conclusiones coherentes entre sí que detallamos a continuación. el equilibrio y la estabilidad, sino que en cambio suponen un incremento de los esfuerzos y tensiones a los que está sometido el terreno. Por lo primero, son prescindibles, y por lo segundo, es recomendable su retirada, siempre que en el proceso de desmontaje no se dañen otros elementos históricos valiosos.

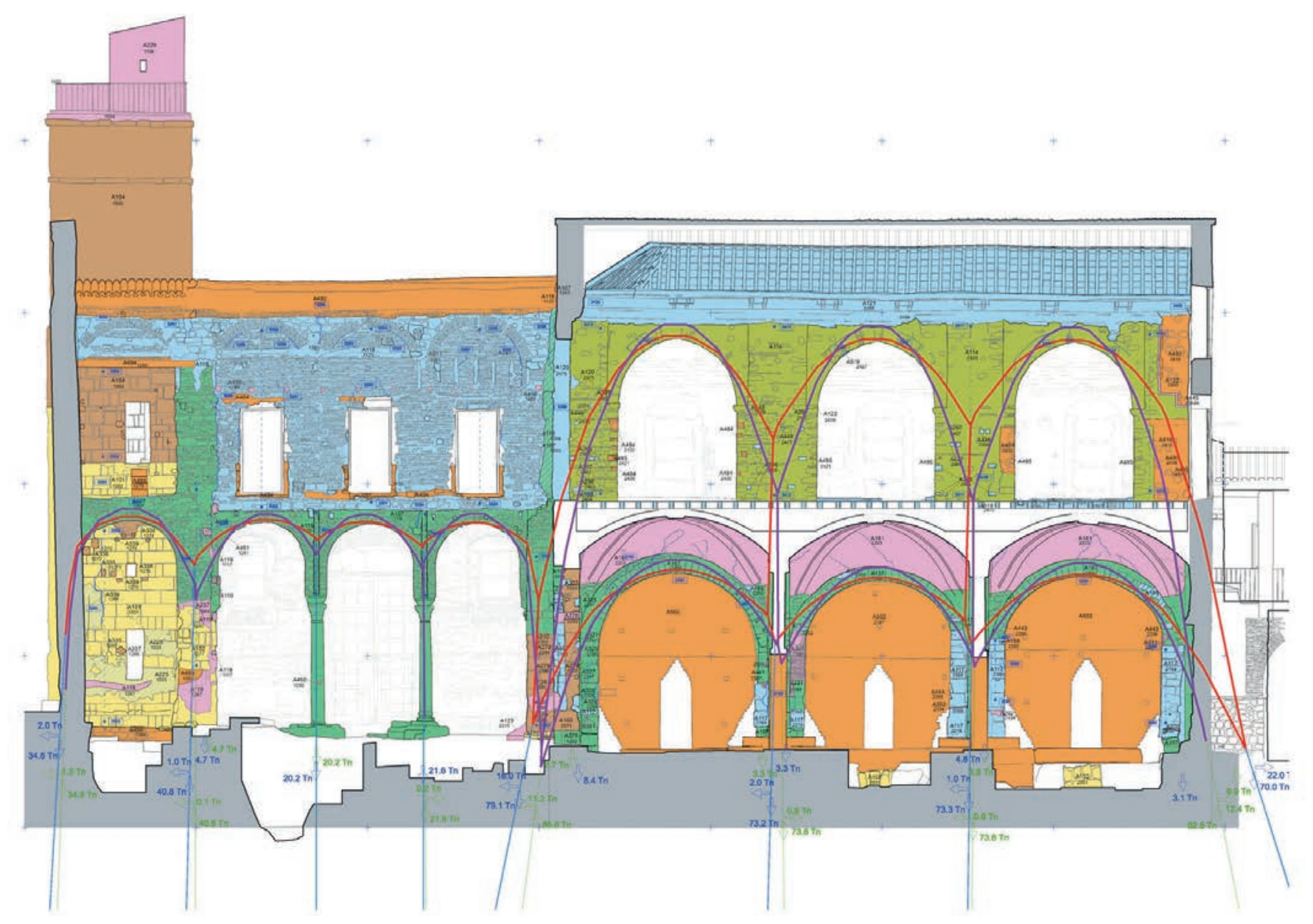

Figura 30. Combinación de cálculo estructural y análisis evolutivo.

La iglesia ha sufrido movimientos generalizados de su estructura provocados principalmente por un deficiente diseño del cimiento que produce en el terreno mayores tensiones de las que éste es capaz de resistir. La mayor parte de esos movimientos se han detenido históricamente, probablemente al haberse alcanzado un grado de consolidación suficiente en el terreno que lo ha hecho más resistente y estable. Sin embargo, en los lados suroeste y noroeste, donde el estrato de rellenos altamente compresible tiene mayor espesor, el movimiento de asiento y giro no se ha detenido todavía.

Los refuerzos realizados en las últimas décadas no sólo no son suficientemente eficaces de cara a restablecer
Los refuerzos en el exterior de los muros son útiles de cara a conseguir grados de seguridad mayores para la estructura frente a posibles seísmos, pues mejoran la capacidad de la fábrica de aceptar estados límites de equilibrio más amplios frente a posibles esfuerzos laterales o cargas verticales de gran magnitud.

Por último, cabe destacar que los cuatro pilares interiores del aula son puntos especialmente delicados, ya que, además de estar sometidos a tensiones relativamente altas, están muy dañados constructiva y materialmente. Del mismo modo, en sus zapatas y en el terreno en que asientan se produce una alta concentración de tensiones que implica un fuerte asiento por lo que existe un serio riesgo de fallo estructural. 


\section{CONCLUSIONES}

\section{Resultados metodológicos generales}

A lo largo del presente artículo se ha descrito una innovadora metodología de análisis integrado de edificios históricos, cuya principal novedad es la combinación del método estratigráfico para el análisis arqueológico de edificios con el estudio patológico de construcciones históricas. Esta integración de enfoques tradicionalmente ajenos entre sí tiene su justificación fundamental en el hecho de compartir un mismo objeto de análisis, el edificio histórico. Su naturaleza pluriestratigráfica, compleja y evolutiva es precisamente la característica fundamental en la cual se basa nuestra propuesta, ya que es la secuencia de transformaciones que el edificio experimenta a lo largo de su historia la columna vertebral que articula la integración de la lectura histórico-constructiva con el estudio de los procesos patológicos.

Es fundamental entender que dichos procesos que afectan al edificio provocando lesiones en forma de desplomes, grietas, erosiones, etc. no son fenómenos estáticos, sino que evolucionan en el tiempo entrelazándose con la secuencia constructiva del edificio. Para alcanzar una rigurosa contextualización de dichos procesos patológicos es necesario un sustento metodológico y unas herramientas de análisis que refuercen los resultados obtenidos. $\mathrm{Y}$ es en este punto donde el diagrama de relaciones estratigráficas se configura como el elemento vinculante principal para entender la evolución material del edificio en relación con las afecciones patológicas que sufre, obteniéndose una secuencia evolutiva completa.

En definitiva, dado que la arquitectura histórica se caracteriza por su naturaleza compleja, los edificios históricos no pueden ser convenientemente entendidos sin su secuencia de transformaciones a lo largo del tiempo. La metodología propuesta no es fruto de una pura especulación teórica, sino que nace de la necesidad de adaptar el análisis a dicha esencia compleja de la arquitectura histórica. Nuestra experiencia nos ha permitido constatar este comportamiento evolutivo de las estructuras históricas y por ello nos ha inducido a desarrollar una metodología adecuada para analizarlas. Así, el método de análisis presentado se fundamenta en un enfoque que considera el desarrollo de los procesos patológicos integrando la dimensión temporal. Esto permite no sólo entender qué ha ocurrido durante la historia pasada del edificio, sino cuáles son las causas del estado actual y qué puede suceder en el futuro. Todo ello será sin duda alguna de gran ayuda de cara a la preservación de los valores culturales, así como a la adecuada gestión y optimización de los recursos disponibles para la conservación del patrimonio cultural, favoreciendo una toma de decisiones más eficiente y racional.

\section{Directrices de intervención en la iglesia de Santa Clara}

Tras la realización del análisis integrado, se ha podido responder sobre la viabilidad de algunas medidas concretas para permitir el acceso del público en condiciones de seguridad suficientes de los muros, bóvedas y forjados del edificio, incluyendo la retirada de los apeos existentes en la planta baja.

Respecto a la retirada de los muros de apeo de los arcos de la planta baja del edificio, se ha concluido que podrían estar sustituyendo a los propios soportes en cruz si estos fallaran definitivamente. Por ello, dichos apeos sólo podrán ser eliminados previa reparación de los soportes. De este modo, se han planteado una serie de actuaciones centradas en la reparación de los pilares del aula, de la base y la escalera de la torre, así como de los muros en puntos críticos para la estabilidad estructural (Fig. 31).

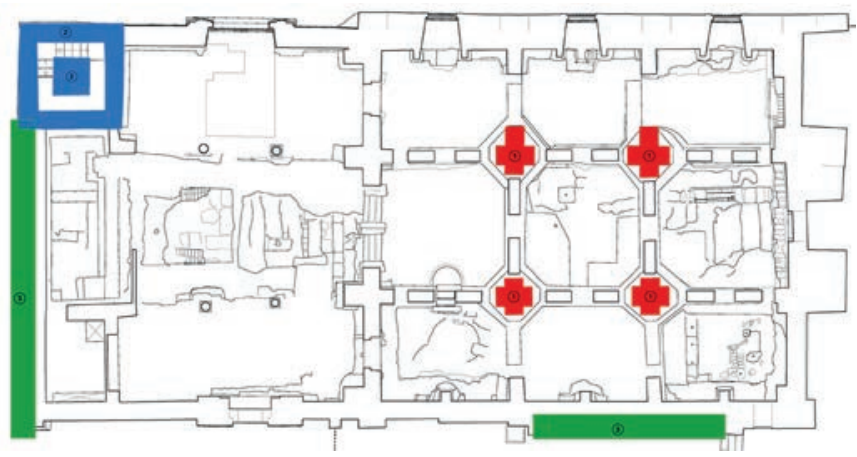

Figura 31. Esquema indicativo de los puntos de intervención.

En todo caso, la intervención se llevará a cabo con técnicas no agresivas y con materiales similares y compatibles con los de la construcción histórica.

\section{Eficiencia de la intervención y optimización de recursos para la conservación}

Como venimos destacando a lo largo del presente artículo, la metodología de análisis integrado que se propone se fundamenta en el rigor del conocimiento de 
la realidad compleja del edificio histórico. Sin embargo, este enfoque metodológico no sólo se justifica por dicho rigor científico, que permite alcanzar un mayor conocimiento del objeto de estudio, sino también porque posibilita una mayor eficiencia en la gestión del patrimonio cultural a través de una mejor preservación de los valores patrimoniales del bien cultural, así como de la reducción de costes de la intervención restauradora y por lo tanto de una optimización de los recursos disponibles para la conservación.

En efecto, el conocimiento integrado de los procesos patológicos en la secuencia evolutiva del edificio permite entender mejor sus causas y su desarrollo a lo largo del tiempo. Por ello, durante la elaboración de las directrices para la conservación se puede, por un lado, decidir si es necesario o no detener los procesos patológicos (en función de la evaluación de los riesgos existentes) y, por otro, establecer unas intervenciones más focalizadas y ajustadas a las necesidades reales del tratamiento de dichos procesos patológicos. Es fundamental entender el edificio y su patología desde un punto de vista evolutivo, como un ente en constante transformación, donde no siempre hay que detener los procesos internos del edificio, sino controlar su desarrollo y limitar los riesgos que se vayan generando.

Este aspecto es de gran importancia, ya que un desconocimiento riguroso y exacto de la patología de la construcción lleva irremediablemente a actuar donde no sería necesario y a desarrollar intervenciones más agresivas, extensas y costosas de lo deseable, por lo que en muchos casos, no sólo no se resuelven los problemas patológicos, sino que se provocan otros. De hecho, las intervenciones inadecuadas provocan habitualmente importantes agresiones al edificio como, por ejemplo, el caso de los refuerzos y las consolidaciones estructurales que van contra la naturaleza mecánica de las estructuras de fábrica, provocando tensiones internas que dañan la estructura histórica. Pero también estas intervenciones afectan gravemente a los valores patrimoniales del bien cultural, eliminando o alterando sustancial e irreversiblemente sus elementos constructivos, de modo que todo ello revierte en una absoluta ineficacia de la acción supuestamente conservadora.

El caso concreto de la iglesia de Santa Clara es muy ilustrativo a este respecto. Las sucesivas intervenciones que se han desarrollado a lo largo de la historia del edificio (centradas muchas de ellas en la adición de masas para el contrarresto de los empujes de los arcos y las bóvedas), no sólo no han parado los movimientos, sino que han provocado nuevas afecciones en el terreno con los consiguientes asientos diferenciales de la estructura que han provocado nuevos daños. Además, el refuerzo de la cimentación con zapatas de hormigón armado ha supuesto la destrucción de parte del yacimiento de época tardoantigua sobre el que se asienta el edificio, perjudicando gravemente el valor patrimonial de este bien cultural (Fig. 32).

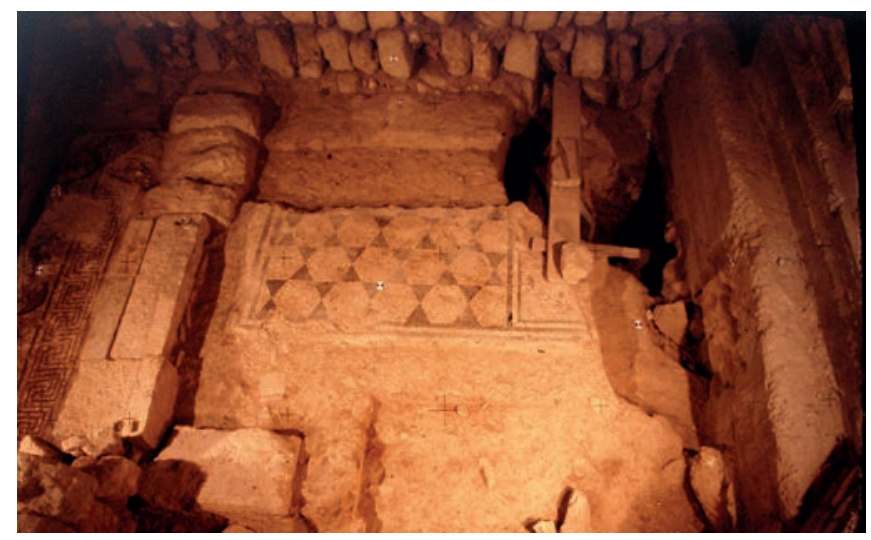

Figura 32. Restos de estructuras tardoantiguas gravemente afectados por los refuerzos de cimentación (parte derecha de la imagen). Imagen realizada por S. L. Latorre y Cámara en el marco del trabajo de levantamiento fotogramétrico.

Los resultados derivados del presente análisis integrado han permitido sin embargo identificar los movimientos activos hoy en día y evaluar el riesgo de cara al uso público. De este modo, se han elaborado unas directrices muy concretas para una intervención de escaso coste, contenida, respetuosa con el edificio y eficaz. Frente a ella, una acción de refuerzo global de la estructura o de intervención en la cimentación y en el terreno (como las que habitualmente se llevan a cabo cuando no se conocen en profundidad las características de la construcción histórica o de sus procesos patológicos) habría sido ineficaz, probablemente provocando nuevos daños al edificio, y habría sido muchísimo más costosa, con el consiguiente malgasto de recursos.

En definitiva, estamos convencidos de que la metodología integrada de análisis histórico, constructivo y patológico, basada en la secuencia estratigráfica y en la realidad compleja de la arquitectura histórica que se describe en este artículo supone grandes beneficios, tanto para el conocimiento de nuestro patrimonio cultural como para la optimización de los recursos para su conservación, de modo que esperamos que pueda servir como referente para futuros trabajos. 


\section{BIBLIOGRAFÍA}

Brogiolo, G. P. 2010: "Procedure di documentazione e processi interpretativi dell'edilizia storica alla luce delle 'Linee Guida per la valutazione e riduzione del rischio sismico del Patrimonio Culturale", Archeologia dell'architettura, XIII, pp. 9-13.

Brogiolo, G. P. y Cagnana, A. 2012: Archeologia dell 'architettura. Metodi e interpretazioni. All'Insegna del Giglio, Firenze.

Caballero Zoreda, L. 2010: "Experiencia metodológica en Arqueología de la Arquitectura de un grupo de investigación", en C. M. Morales y E. de Vega García (eds.), Arqueología aplicada al estudio e intervención de edificios históricos. Últimas tendencias metodológicas, pp. 103-119. Ministerio de Cultura, Madrid. http://www.calameo.com/read/000075335b34985f34eff

Cámara Muñoz, L. y Latorre González-Moro, P. 2002: "Anamnesis de una estructura. La Catedral de Vitoria entre los siglos XII y XX”, Arqueología de la Arquitectura, 1, pp. 145-158.

Cámara Muñoz, L. 2010: "Estratigrafía, evolución estructural y restauración. El caso de la iglesia de Santa Eulalia en Marquínez (Álava)", Arqueología de la Arquitectura, 7, pp. 225-260.
Escribano Ucelay, V. 1964-1965: "Mezquita de la calle Rey Heredia", AlMulk, 4, pp. 83-101.

Harris, E. C. 1979: Principles of Archaeological Stratigraphy. Academic Press, London.

Hernández Giménez, F. 1975: "Alminar de Santa Clara de Córdoba”, en El alminar de 'Abd al-Rahman III en la mezquita mayor de Córdoba. Génesis y repercusiones, pp. 203-208. Patronato de la Alhambra, Granada.

Heyman, J. 1999: El esqueleto de piedra. Mecánica de las estructuras de fábrica. Instituto Juan de Herrera, Madrid.

Marfil Ruiz, P. 1996: "El templo paleocristiano descubierto en la antigua iglesia del convento de Santa Clara, de Córdoba”, Boletín de la Real Academia de Córdoba de Ciencias, Bellas Letras y Nobles Artes, 131, pp. 197-210.

Martín Talaverano, R. 2014: "Documentación gráfica de edificios históricos: principios, aplicaciones y perspectivas", Arqueología de la Arquitectura, 11: e011, https://doi.org/10.3989/arq.arqt.2014.014

Utrero Agudo, M. á. 2009: "Las iglesias cruciformes del siglo VII en la Península Ibérica. Novedades y problemas cronológicos y morfológicos de un tipo arquitectónico", en L. Caballero Zoreda, P. Mateos Cruz y M. ${ }^{\mathrm{a}}$ Á. Utrero Agudo (eds.), El siglo VII frente al siglo VII. Arquitectura, pp. 133-154. CSIC, Madrid. 